\title{
Local amplification of highly pathogenic avian influenza H5N8 viruses in wild birds in the Netherlands, 2016 to 2017
}

Marjolein J. Poen ${ }^{1}$, Theo M. Bestebroer ${ }^{1}$, Oanh Vuong ${ }^{1}$, Rachel D. Scheuer ${ }^{1}$, Henk P. van der Jeugd ${ }^{2,3}$, Erik Kleyheeg ${ }^{2,3}$, Dirk

Eggink $^{1,4}$, Pascal Lexmond ${ }^{1}$, Judith M.A. van den Brand ${ }^{1}$, Lineke Begeman ${ }^{1}$, Stefan van der Vliet ${ }^{1}$, Gerhard J.D.M. Müskens ${ }^{5}$, Frank A. Majoor ${ }^{6}$, Marion P.G. Koopmans ${ }^{1}$, Thijs Kuiken ${ }^{1}$, Ron A.M. Fouchier ${ }^{1}$

1. Erasmus MC, Department of Viroscience, Rotterdam, the Netherlands

2. Netherlands Institute of Ecology (NIOO-KNAW), Department of Animal Ecology, Wageningen, the Netherlands

3. Vogeltrekstation - Dutch Centre for Avian Migration and Demography (NIOO-KNAW), Wageningen, the Netherlands

4. Academic Medical Center Amsterdam, Laboratory of Experimental Virology, Amsterdam, the Netherlands

5. Alterra, Center for Ecosystem Studies, Wageningen University, Wageningen, the Netherlands

6. Sovon, Dutch Centre for Field Ornithology, Nijmegen, the Netherlands

Correspondence: Ron A M Fouchier (r.fouchier@erasmusmc.nl)

Citation style for this article:

Poen Marjolein J., Bestebroer Theo M., Vuong Oanh, Scheuer Rachel D., van der Jeugd Henk P., Kleyheeg Erik, Eggink Dirk, Lexmond Pascal, van den Brand Judith M.A., Begeman Lineke, van der Vliet Stefan, Müskens Gerhard J.D.M., Majoor Frank A., Koopmans Marion P.G., Kuiken Thijs, Fouchier Ron A.M.. Local amplification of highly pathogenic avian influenza $\mathrm{H}_{5} \mathrm{~N} 8$ viruses in wild birds in the Netherlands, 2016 to 2017. Euro Surveill. 2018;23(4):pii=17-00449. https://doi. org/10.2807/1560-7917.ES.2018.23.4.17-00449

Article submitted on 05 Jul 2017 / accepted on 05 Dec 2017 / published on 25 Jan 2017

Introduction: Highly pathogenic avian influenza (HPAI) viruses of subtype $\mathrm{H}_{5} \mathrm{~N} 8$ were re-introduced into the Netherlands by late 2016, after detections in southeast Asia and Russia. This second $\mathrm{H}_{5} \mathrm{~N} 8$ wave resulted in a large number of outbreaks in poultry farms and the deaths of large numbers of wild birds in multiple European countries. Methods: Here we report on the detection of HPAI $\mathrm{H}_{5} \mathrm{~N} 8$ virus in 57 wild birds of 12 species sampled during active $(32 / 5,167)$ and passive (25/36) surveillance activities, i.e. in healthy and dead animals respectively, in the Netherlands between 8 November 2016 and 31 March 2017. Moreover, we further investigate the experimental approach of wild bird serology as a contributing tool in HPAl outbreak investigations. Results: In contrast to the first $\mathrm{H}_{5} \mathrm{~N} 8$ wave, local virus amplification with associated wild bird mortality has occurred in the Netherlands in 2016/17, with evidence for occasional gene exchange with low pathogenic avian influenza (LPAI) viruses. Discussion: These apparent differences between outbreaks and the continuing detections of HPAl viruses in Europe are a cause of concern. With the current circulation of zoonotic HPAI and LPAI virus strains in Asia, increased understanding of the drivers responsible for the global spread of Asian poultry viruses via wild birds is needed.

\section{Introduction}

Highly pathogenic avian influenza (HPAI) viruses of the $\mathrm{H}_{5}$ subtype, originating from the $\mathrm{A} / \mathrm{Goose} /$ Guangdong/1/1996 (GsGd) lineage, have been circulating continuously in poultry in south-east Asia since 1997 and have also been detected frequently in wild birds [1]. In 2014, a new HPAI H5N8 virus of this GsGd lineage of clade 2.3.4.4 emerged globally. This first intercontinental wave of $\mathrm{HPAI} \mathrm{H}_{5} \mathrm{~N} 8$ started with virus detections in south-east Asia from early 2014 onwards in both poultry and wild birds [2-4]. By the end of 2014, this HPAI $\mathrm{H}_{5} \mathrm{~N} 8$ virus simultaneously spread to Europe and North America through long distance migratory birds [5]. In North America, the virus reassorted with local low pathogenic avian influenza (LPAI) viruses causing a massive number of outbreaks and associated economical loss [6]. In Europe, this first wave caused a relative limited number of outbreaks in poultry holdings, and was detected in some wild birds between November 2014 and February 2015 [7,8]. During the spring and summer of 2015 , occasional detections of HPAI $\mathrm{H}_{5} \mathrm{~N} 8$ were reported in south-east Asia [9]. To assess the risk of virus re-introduction by wintering birds arriving in Europe by the autumn of 2015, intensified active surveillance (i.e. surveillance in living birds) was performed in the Netherlands from September to December 2015. This surveillance provided virological and serological evidence that the HPAI $\mathrm{H}_{5} \mathrm{~N} 8$ virus had disappeared from the European (wintering) wild bird population with no virus detections in any of the tested birds and a decreased seroprevalence of HPAI $\mathrm{H}_{5}$ clade 2.3.4.4-specific antibodies, suggesting no massive viral replication in the 2015 breeding season [10].

However, in June 2016, the detection of HPAI H5N8 in wild birds of multiple species on their breeding grounds was reported around Uvs-Nuur Lake in Russia [11]. In contrast to the 2014 emerging strains, which belong to group A (A/broiler duck/Korea/Buan2/2014-like), 


\section{FIGURE 1}

Overview of wild bird surveillance activities in the Netherlands between 1 February 2016 and 31 March 2017, with intensified surveillance from 13 November-31 December 2016 and 8-19 February 2017
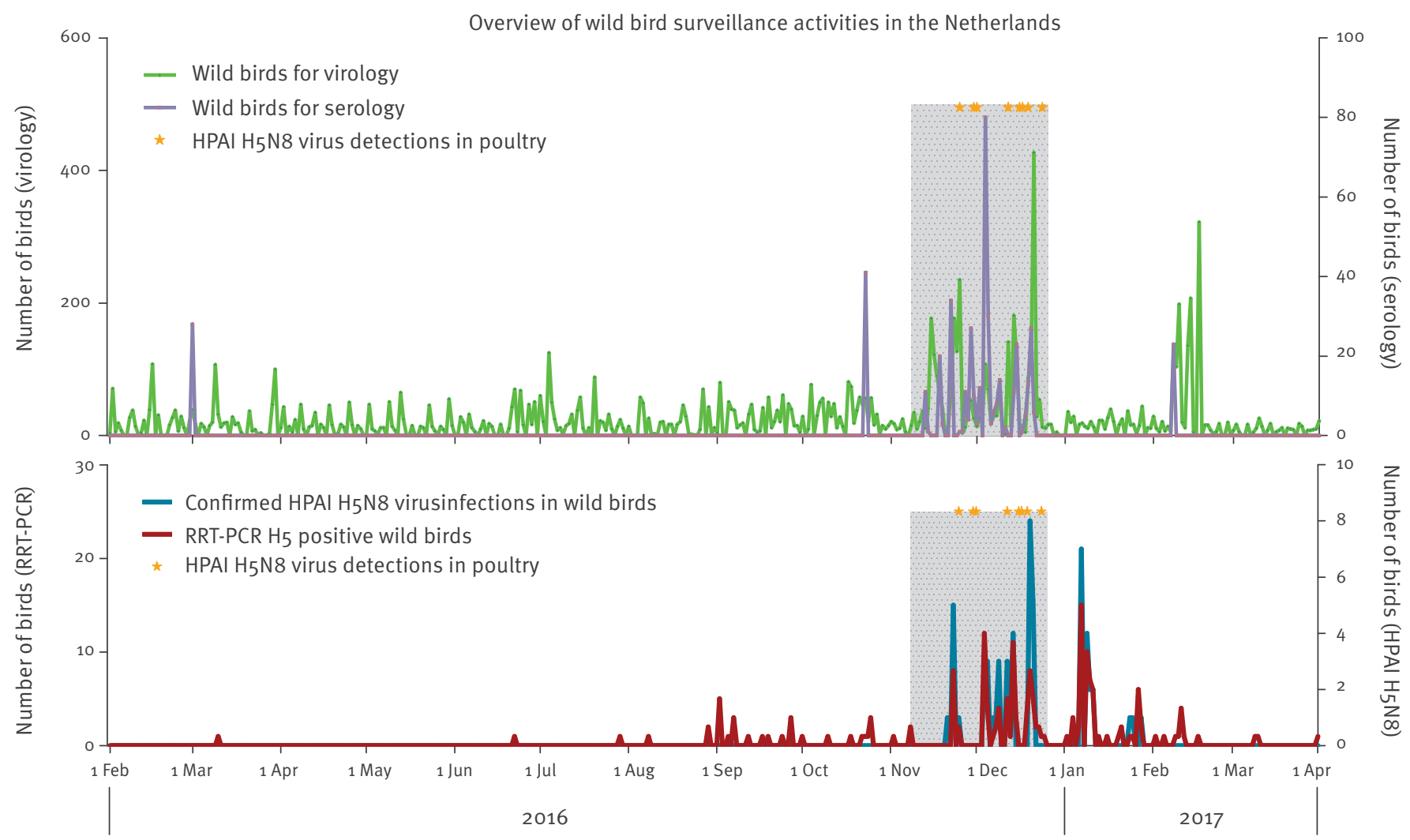

RRT-PCR: real-time reverse-transcription PCR.

Displayed over time are the number of birds tested for virus presence (green line), the number of birds positive for $\mathrm{H}_{5}$ in the RRT-PCR (dark red line) with the number of confirmed HPAI H5N8 cases (blue line), and the number of birds included for serology (purple line). In addition, the period with the largest wild-bird die-offs (light grey box) and the HPAI H5N8 detections in commercial poultry in the Netherlands (orange stars) are displayed.

\section{FIGURE 2}

Tanglegram of highly pathogenic avian influenza H5 clade 2.3.4.4 virus (left) and the accompanying N8 genes (right) based on 250 bootstraps

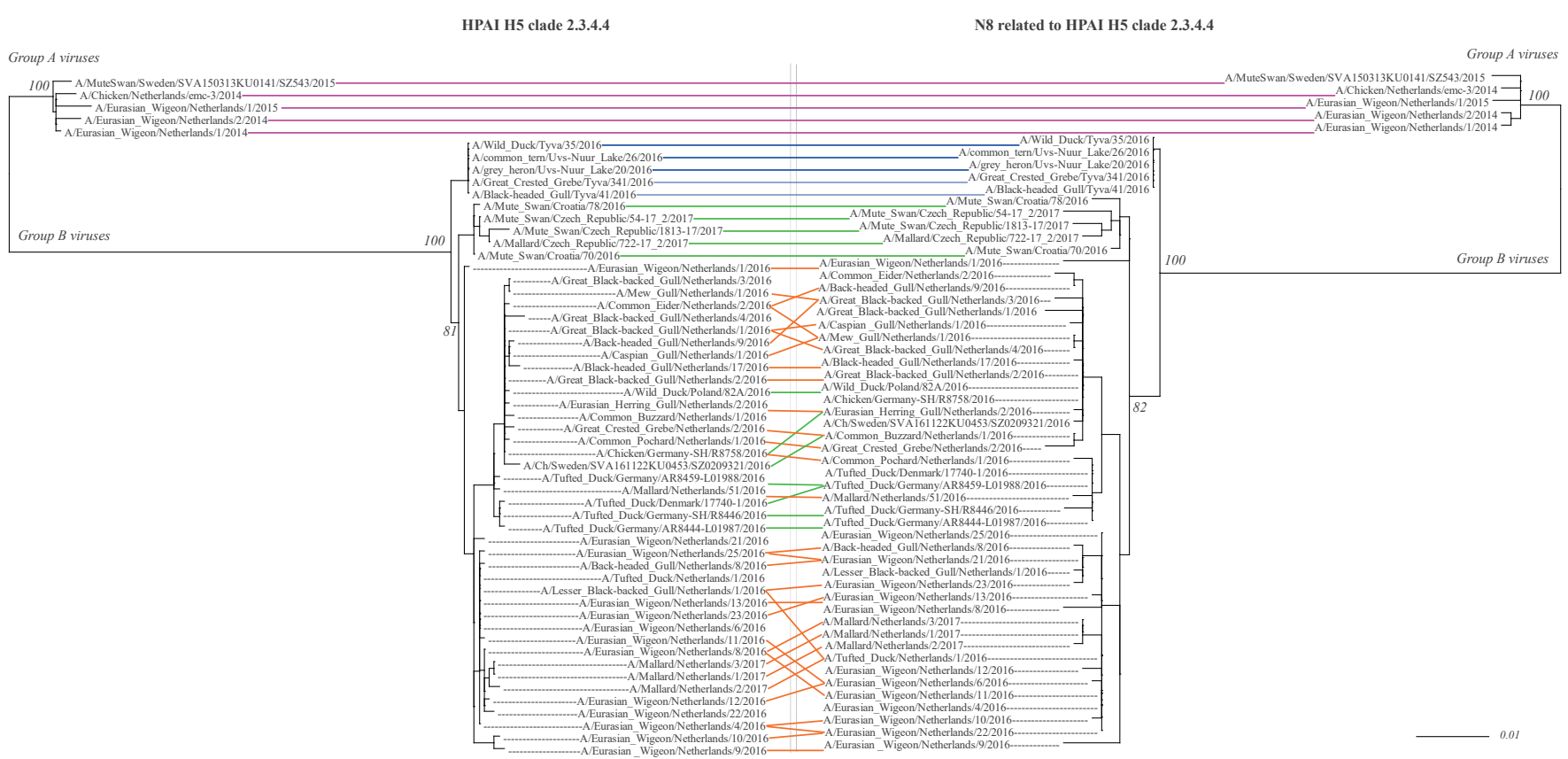

Only bootstrap values above $70 \%$ are shown. The $2014 / 15$ group A $\mathrm{H}_{5}$ viruses with their $\mathrm{N} 8$ genes (pink) are phylogenetically distinct from the 2016/17 group B viruses first detected in Russia (Tyva and Uvs-Nuur Lake) in May-June 2016 (blue) and later in other European countries (green) and the Netherlands (orange). 
this virus belonged to group $\mathrm{B}$ (A/breeder duck/Korea/ Gochang1/2014-like) viruses [4,11]. These group B viruses had been detected previously in China and South Korea in 2014, but had not been reported since [3,12]. From mid-October 2016 onwards, group B lineage HPAI $\mathrm{H}_{5} \mathrm{~N} 8$ viruses were detected in both India [13] and in European countries. Unlike the 2014/15 group A viruses, group B viruses caused local die-offs of wild birds in many countries, often resulting in wild bird deaths preceding those in poultry [14-16]. The introduction of these group B HPAI $\mathrm{H}_{5} \mathrm{~N} 8$ viruses in the Netherlands was marked by a die-off of tufted ducks (Aythya fuligula) and great crested grebes (Podiceps cristatus) in the Gouwzee $\left(52^{\circ} 27^{\prime} \mathrm{O} 9^{\prime \prime} \mathrm{N}, 5^{\circ} \mathrm{O} 4^{\prime} \mathrm{O} 7^{\prime \prime} \mathrm{E}\right)$, a large fresh water lake, on 8 November $2016[14,17]$. Most of the internal genes of this 'second wave' HPAI $\mathrm{H}_{5} \mathrm{~N} 8$ virus were derived from Eurasian LPAI viruses via reassortment, after their original detection in China and South Korea in 2014 and Russia in May 2016 $[11,15]$. Occasional reassortment of the neuraminidase (NA) gene also led to a few detections of clade 2.3.4.4 HPAI $\mathrm{H}_{5} \mathrm{~N}_{5}$ and $\mathrm{H}_{5} \mathrm{~N} 6$ viruses [18].

Wild migratory birds were shown to be the most probable vectors for the first global spread of HPAI $\mathrm{H}_{5} \mathrm{~N} 8$ in 2014 that coincided with the timing and flyways of the autumn migration, based on a recent worldwide phylogenetic study of $\mathrm{HPAI} \mathrm{H}_{5} \mathrm{~N} 8$ viruses $[5,19]$. These avian influenza viruses constitute a constant animal and human health threat, where the risk in part is determined by the (evolving) genomic constitution of the circulating viruses. It is therefore of crucial importance to actively monitor influenza viruses and their evolution in wild bird populations, to monitor trends and diversity of circulating viruses, and to assess the risk of spread for strains that are unusual in their genetic make-up and/or spread for animal and human health. In this study we have performed intense active surveillance in wild birds in the Netherlands in response to the HPAI H5N8 introduction in Europe in late 2016. We performed both virological and serological studies to attempt to identify wild bird species that might contribute to the spread and maintenance of this virus.

\section{Methods}

\section{Ethical statement}

The capture of free-living birds was approved by the Dutch Ministry of Economic Affairs based on the Flora and Fauna Act (permit number $\mathrm{FF} / 75 \mathrm{~A} / 2009 / 067$, $\mathrm{FF} / 75 \mathrm{~A} / 2014 / 054$ and licence number 951 to Vogeltrekstation NIOO-KNAW). Handling and sampling of free-living birds was approved by the Animal Experiment Committee of the Erasmus Medical Center (permit number 122-11-31). Free-living birds were released into the wild after sampling and all efforts were made to minimise animal suffering throughout the procedures.

\section{Study population}

A continuous active surveillance programme of resident and migrating wild birds for avian influenza viruses is in place in the Netherlands. The ongoing surveillance efforts were intensified in response to the first detection of HPAI $\mathrm{H}_{5} \mathrm{~N} 8$ virus in the Netherlands in 2016 between 13 November and 31 December 2016, the period during which mortality among wild birds and outbreaks in poultry holdings were occurring in the country, and from 8 February until 19 February 2017, when die-offs of wild birds and outbreaks in poultry had ceased. On 1 March and 23 October 2016, as well as approximately during the first period of intensified surveillance (13 November to 21 December 2016), and on 8 February 2017, blood samples were obtained in addition to samples for virus detection.

\section{Sample collection}

Live wild birds were captured using duck decoys, cannon nets, leg nooses, swan hooks, or manually. Birds were sampled routinely for virus detection using oropharyngeal and cloacal swabs as described elsewhere [10]. In addition, fresh faecal samples were collected from Eurasian wigeons (Anas penelope) for virus detection. Fresh faecal samples were collected by trained ornithologists able to distinguish species-specific droppings from locations where large homogeneous groups of Eurasian wigeons were foraging in the field. Blood samples were collected for serum antibody detection as described previously [10]. In addition to active surveillance, oropharyngeal and/or cloacal swabs of a limited number of freshly dead wild birds were opportunistically collected for virus detection (i.e. passive surveillance).

Virus detection, isolation and characterisation Samples for virus detection were analysed for the presence of $\mathrm{HPAI}_{5} \mathrm{H}_{5} \mathrm{~N} 8$ ) virus using matrix- and $\mathrm{H}_{5}$-specific real-time reverse-transcription PCR (RRT-PCR) assays, followed by haemagglutinin (HA) and NA gene sequencing as previously described [7]. Samples testing positive in matrix and $\mathrm{H}_{5}$ specific RRT-PCR were inoculated in Madin-Darby canine kidney (MDCK) cells. Samples were characterised as HPAI $\mathrm{H}_{5}$ virus by detection of a multi-basic cleavage site upon Sanger sequencing of the HA gene.

\section{Virus sequencing and phylogeny}

Full length HA and NA sequences of all virus isolates and full genome sequences for a subset of these were obtained by Sanger sequencing. All sequences were deposited in a public database (http://www.gisaid. com). Primer sequences are available upon request.

For HA and NA phylogeny, sequences obtained in this study were supplemented with publicly available sequences of HPAI $\mathrm{H}_{5}$ viruses of clade 2.3.4.4 detected globally between 2014 and 2017. These additional sequences were obtained from the Global Initiative on Sharing Avian Influenza Data database (http://www. gisaid.com) on 20 May 2017 (Table 1). 
TABLE 1A

Acknowledgements of authors, and originating and submitting laboratories providing the sequences used for phylogenetic analysis

\begin{tabular}{|c|c|c|c|c|c|}
\hline Isolate ID & Isolates name & $\begin{array}{l}\text { Collection } \\
\text { date }\end{array}$ & $\begin{array}{l}\text { Originating } \\
\text { laboratory }\end{array}$ & $\begin{array}{l}\text { Submitting } \\
\text { Laboratory }\end{array}$ & Authors \\
\hline $\begin{array}{l}\text { EPI_ } \\
\text { ISL_257700 }\end{array}$ & A/Mute_Swan/Czech_Republic/1813-17/2017 & 5 Feb 2017 & Not listed & $\begin{array}{l}\text { State Veterinary } \\
\text { Institute Prague }\end{array}$ & Nagy, A. \\
\hline $\begin{array}{l}\text { EPI_- } \\
\text { ISL_250885 }\end{array}$ & A/Mute_Swan/Czech_Republic/54-17_2/2017 & 2 Jan 2017 & Not listed & $\begin{array}{l}\text { State Veterinary } \\
\text { Institute Prague }\end{array}$ & Nagy, A. \\
\hline $\begin{array}{l}\text { EPI_- } \\
\text { ISL_248663 }\end{array}$ & A/Mallard/Czech_Republic/722-17_2/2017 & 15 Jan 2017 & Not listed & $\begin{array}{l}\text { State Veterinary } \\
\text { Institute Prague }\end{array}$ & Nagy, A. \\
\hline $\begin{array}{l}\text { EPI_ } \\
\text { ISL_247713 }\end{array}$ & A/Tufted_Duck/Denmark/17740-1/2016 & 8 Nov 2016 & $\begin{array}{l}\text { Technical } \\
\text { University of } \\
\text { Denmark }\end{array}$ & $\begin{array}{c}\text { Animal and Plant } \\
\text { Health Agency } \\
\text { (APHA) }\end{array}$ & $\begin{array}{l}\text { Hjulsager CK, Krog JS, } \\
\text { Larsen LE, Kvisgaard LK, } \\
\text { Essen S }\end{array}$ \\
\hline $\begin{array}{l}\text { EPI_- } \\
\text { ISL_238197 }\end{array}$ & A/Mute_Swan/Croatia/78/2016 & $\begin{array}{l}12 \text { Nov } \\
2016\end{array}$ & Not listed & $\begin{array}{l}\text { Croatian } \\
\text { Veretinary } \\
\text { Institute } \\
\end{array}$ & Not listed \\
\hline $\begin{array}{l}\text { EPI_- } \\
\text { ISL_238196 }\end{array}$ & A/Mute_Swan/Croatia/70/2016 & $\begin{array}{l}300 \mathrm{ct} \\
2016\end{array}$ & Not listed & $\begin{array}{l}\text { Croatian } \\
\text { Veretinary } \\
\text { Institute } \\
\end{array}$ & Not listed \\
\hline $\begin{array}{l}\text { EPI_- } \\
\text { ISL_237945 }\end{array}$ & A/Tufted_Duck/Germany/AR8459-Lo1988/2016 & 8 Nov 2016 & Not listed & $\begin{array}{c}\text { Friedrich-Loeffler- } \\
\text { Institut }\end{array}$ & Not listed \\
\hline $\begin{array}{l}\text { EPI_- } \\
\text { ISL_237944 }\end{array}$ & A/Tufted_Duck/Germany/AR8444-L01987/2016 & 7 Nov 2016 & Not listed & $\begin{array}{c}\text { Friedrich-Loeffler- } \\
\text { Institut }\end{array}$ & Not listed \\
\hline $\begin{array}{l}\text { EPI_ } \\
\text { ISL_237732 }\end{array}$ & A/Tufted_Duck/Germany-SH/R8446/2016 & 7 Nov 2016 & Not listed & $\begin{array}{c}\text { Friedrich-Loeffler- } \\
\text { Institut }\end{array}$ & Not listed \\
\hline $\begin{array}{l}\text { EPI_- } \\
\text { ISL_238039 }\end{array}$ & A/Chicken/Germany-SH/R8758/2016 & $\begin{array}{c}11 \text { Nov } \\
2016\end{array}$ & Not listed & $\begin{array}{c}\text { Friedrich-Loeffler- } \\
\text { Institut }\end{array}$ & Not listed \\
\hline $\begin{array}{l}\text { EPI_- } \\
\text { ISL_237921 }\end{array}$ & A/Wild_Duck/Poland/82A/2016 & 2 Nov 2016 & Not listed & $\begin{array}{c}\text { National } \\
\text { Veterinary } \\
\text { Research Institut } \\
\text { Poland } \\
\end{array}$ & Świętoń E, Śmietanka K \\
\hline $\begin{array}{l}\text { EPI_ } \\
\text { ISL_175535 }\end{array}$ & $\begin{array}{l}\text { A/MuteSwan/Sweden/SVA150313KU0141/ } \\
\text { SZ543/2015 }\end{array}$ & 5 Mar 2015 & $\begin{array}{l}\text { National } \\
\text { Veterinary } \\
\text { Institute, } \\
\text { Sweden }\end{array}$ & $\begin{array}{c}\text { National } \\
\text { Veterinary } \\
\text { Institute, Sweden }\end{array}$ & $\begin{array}{l}\text { Zohari S, Ullman K, } \\
\text { Olofsson A }\end{array}$ \\
\hline $\begin{array}{l}\text { EPI_- } \\
\text { ISL_238896 }\end{array}$ & $\begin{array}{c}\text { A/Chicken/Sweden/SVA161122KU0453/ } \\
\text { SZo209321/2016 }\end{array}$ & $\begin{array}{l}21 \text { Nov } \\
2016\end{array}$ & $\begin{array}{l}\text { National } \\
\text { Veterinary } \\
\text { Institute, } \\
\text { Sweden }\end{array}$ & $\begin{array}{c}\text { National } \\
\text { Veterinary } \\
\text { Institute, Sweden }\end{array}$ & Not listed \\
\hline $\begin{array}{l}\text { EPI_- } \\
\text { ISL_231685 }\end{array}$ & A/Black-headed_Gull/Tyva/41/2016 & $\begin{array}{l}25 \text { May } \\
2016\end{array}$ & $\begin{array}{l}\text { State Research } \\
\text { Center of } \\
\text { Virology and } \\
\text { Biotechnology } \\
\text { (VECTOR) }\end{array}$ & $\begin{array}{l}\text { WHO National } \\
\text { Influenza } \\
\text { Centre Russian } \\
\text { Federation }\end{array}$ & $\begin{array}{l}\text { Fadeev A, Komissarov A, } \\
\text { Egorova A, Sintsova K, } \\
\text { Musaeva T, Susloparov I, } \\
\text { Marchenko V, Ryzhikov A }\end{array}$ \\
\hline $\begin{array}{l}\text { EPI_- } \\
\text { ISL_231684 }\end{array}$ & A/Wild_Duck/Tyva/35/2016 & $\begin{array}{l}25 \text { May } \\
2016\end{array}$ & $\begin{array}{l}\text { State Research } \\
\text { Center of } \\
\text { Virology and } \\
\text { Biotechnology } \\
\text { (VECTOR) }\end{array}$ & $\begin{array}{l}\text { WHO National } \\
\text { Influenza } \\
\text { Centre Russian } \\
\text { Federation }\end{array}$ & $\begin{array}{l}\text { Fadeev A, Komissarov A, } \\
\text { Egorova A, Sintsova K, } \\
\text { Musaeva T, Susloparov I, } \\
\text { Marchenko V, Ryzhikov A }\end{array}$ \\
\hline $\begin{array}{l}\text { EPI_- } \\
\text { ISL_224580 }\end{array}$ & A/Great_Crested_Grebe/Tyva/341/2016 & $\begin{array}{l}25 \text { May } \\
2016\end{array}$ & $\begin{array}{l}\text { Research } \\
\text { Institute of } \\
\text { Experimental } \\
\text { and Clinical } \\
\text { Medicine } \\
\end{array}$ & $\begin{array}{l}\text { Research Institute } \\
\text { of Experimental } \\
\text { and Clinical } \\
\text { Medicine }\end{array}$ & $\begin{array}{l}\text { Sharshov K, Kurskaya } \\
\text { O, Sobolev I, Alekseev } \\
\text { A, Alikina T, Kabilov M, } \\
\text { Shestopalov A }\end{array}$ \\
\hline $\begin{array}{l}\text { EPI_- } \\
\text { ISL_234057 }\end{array}$ & A/grey_heron/Uvs-Nuur_Lake/20/2016 & $\begin{array}{l}25 \text { May } \\
2016\end{array}$ & $\begin{array}{l}\text { Research } \\
\text { Institute of } \\
\text { Experimental } \\
\text { and Clinical } \\
\text { Medicine }\end{array}$ & $\begin{array}{l}\text { Research Institute } \\
\text { of Experimental } \\
\text { and Clinical } \\
\text { Medicine }\end{array}$ & $\begin{array}{c}\text { Sharshov K, Kurskaya O, } \\
\text { Sobolev I, Alekseev A, } \\
\text { Shestopalov A }\end{array}$ \\
\hline $\begin{array}{l}\text { EPI_- } \\
\text { ISL_234058 }\end{array}$ & A/common_tern/Uvs-Nuur_Lake/26/2016 & $\begin{array}{l}25 \text { May } \\
2016\end{array}$ & $\begin{array}{l}\text { Research } \\
\text { Institute of } \\
\text { Experimental } \\
\text { and Clinical } \\
\text { Medicine }\end{array}$ & $\begin{array}{l}\text { Research Institute } \\
\text { of Experimental } \\
\text { and Clinical } \\
\text { Medicine }\end{array}$ & $\begin{array}{l}\text { Sharshov K, Kurskaya } \\
\text { O, Sobolev I, Alekseev } \\
\text { A, Alikina T, Kabilov M, } \\
\text { Shestopalov A }\end{array}$ \\
\hline $\begin{array}{l}\text { EPI_ } \\
\text { ISL_269601 }\end{array}$ & A/Eurasian_Herring_Gull/Netherlands/2/2016 & $\begin{array}{l}20 \mathrm{Dec} \\
2016\end{array}$ & $\begin{array}{l}\text { Erasmus } \\
\text { Medical Center }\end{array}$ & $\begin{array}{l}\text { Erasmus Medical } \\
\text { Center }\end{array}$ & $\begin{array}{c}\text { Poen,MJ, Van Der } \\
\text { Jeugd,HP, Vuong,0, } \\
\text { Scheuer,RD, Fouchier,RAM } \\
\text { et al. }\end{array}$ \\
\hline
\end{tabular}


Acknowledgements of authors, and originating and submitting laboratories providing the sequences used for phylogenetic analysis

\begin{tabular}{|c|c|c|c|c|c|}
\hline Isolate ID & Isolates name & $\begin{array}{l}\text { Collection } \\
\text { date }\end{array}$ & $\begin{array}{l}\text { Originating } \\
\text { laboratory }\end{array}$ & $\begin{array}{l}\text { Submitting } \\
\text { Laboratory }\end{array}$ & Authors \\
\hline $\begin{array}{l}\text { EPI_ } \\
\text { ISL_268916 }\end{array}$ & A/Caspian_Gull/Netherlands/1/2016 & $\begin{array}{l}20 \mathrm{Dec} \\
2016\end{array}$ & $\begin{array}{c}\text { Erasmus } \\
\text { Medical Center }\end{array}$ & $\begin{array}{l}\text { Erasmus Medical } \\
\text { Center }\end{array}$ & $\begin{array}{c}\text { Poen,MJ, Van Der } \\
\text { Jeugd,HP, Vuong,O, } \\
\text { Scheuer,RD, Fouchier, RAM } \\
\text { et al. }\end{array}$ \\
\hline $\begin{array}{l}\text { EPI_ } \\
\text { ISL_255910 }\end{array}$ & A/Mew Gull/Netherlands/1/2016 & $\begin{array}{l}23 \text { Nov } \\
2016\end{array}$ & $\begin{array}{c}\text { Erasmus } \\
\text { Medical Center }\end{array}$ & $\begin{array}{l}\text { Erasmus Medical } \\
\text { Center }\end{array}$ & $\begin{array}{c}\text { Poen,MJ, Van Der } \\
\text { Jeugd,HP, Vuong, } 0 \text {, } \\
\text { Scheuer,RD, Fouchier,RAM } \\
\text { et al. }\end{array}$ \\
\hline $\begin{array}{l}\text { EPI_ } \\
\text { ISL_269602 }\end{array}$ & $\begin{array}{c}\text { A/Lesser_Black-backed_Gull/ } \\
\text { Netherlands/1/2016 }\end{array}$ & $\begin{array}{l}20 \mathrm{Dec} \\
2016\end{array}$ & $\begin{array}{l}\text { Erasmus } \\
\text { Medical Center }\end{array}$ & $\begin{array}{l}\text { Erasmus Medical } \\
\text { Center }\end{array}$ & $\begin{array}{c}\text { Poen,MJ, Van Der } \\
\text { Jeugd,HP, Vuong,O, } \\
\text { Scheuer,RD, Fouchier,RAM } \\
\text { et al. }\end{array}$ \\
\hline $\begin{array}{l}\text { EPI_- } \\
\text { ISL_269697 }\end{array}$ & $\begin{array}{c}\text { A/Great_Black-backed_Gull/ } \\
\text { Netherlands/2/2016 }\end{array}$ & $\begin{array}{l}23 \text { Nov } \\
2016\end{array}$ & $\begin{array}{c}\text { Erasmus } \\
\text { Medical Center }\end{array}$ & $\begin{array}{l}\text { Erasmus Medical } \\
\text { Center }\end{array}$ & $\begin{array}{c}\text { Poen,MJ, Van Der } \\
\text { Jeugd,HP, Vuong,O, } \\
\text { Scheuer,RD, Fouchier,RAM } \\
\text { et al. }\end{array}$ \\
\hline $\begin{array}{l}\text { EPI_ } \\
\text { ISL_269599 }\end{array}$ & $\begin{array}{c}\text { A/Great_Black-backed_Gull/ } \\
\text { Netherlands/4/2016 }\end{array}$ & $\begin{array}{l}14 \mathrm{Dec} \\
2016\end{array}$ & $\begin{array}{l}\text { Erasmus } \\
\text { Medical Center }\end{array}$ & $\begin{array}{l}\text { Erasmus Medical } \\
\text { Center }\end{array}$ & $\begin{array}{c}\text { Poen,MJ, Van Der } \\
\text { Jeugd,HP, Vuong,O, } \\
\text { Scheuer,RD, Fouchier,RAM } \\
\text { et al. }\end{array}$ \\
\hline $\begin{array}{l}\text { EPI_- } \\
\text { ISL_269598 }\end{array}$ & $\begin{array}{c}\text { A/Great_Black-backed_Gull/ } \\
\text { Netherlands/3/2016 }\end{array}$ & $\begin{array}{l}23 \text { Nov } \\
2016\end{array}$ & $\begin{array}{c}\text { Erasmus } \\
\text { Medical Center }\end{array}$ & $\begin{array}{l}\text { Erasmus Medical } \\
\text { Center }\end{array}$ & $\begin{array}{c}\text { Poen,MJ, Van Der } \\
\text { Jeugd,HP, Vuong,0, } \\
\text { Scheuer,RD, Fouchier,RAM } \\
\text { et al. }\end{array}$ \\
\hline $\begin{array}{l}\text { EPI_- } \\
\text { ISL_269597 }\end{array}$ & $\begin{array}{c}\text { A/Great_Black-backed_Gull/ } \\
\text { Netherlands/1/2016 }\end{array}$ & $\begin{array}{l}23 \text { Nov } \\
2016\end{array}$ & $\begin{array}{c}\text { Erasmus } \\
\text { Medical Center }\end{array}$ & $\begin{array}{l}\text { Erasmus Medical } \\
\text { Center }\end{array}$ & $\begin{array}{c}\text { Poen,MJ, Van Der } \\
\text { Jeugd,HP, Vuong,O, } \\
\text { Scheuer,RD, Fouchier,RAM } \\
\text { et al. }\end{array}$ \\
\hline $\begin{array}{l}\text { EPI_- } \\
\text { ISL_255892 }\end{array}$ & A/Great Black-backed Gull/Netherlands/2/2016 & $\begin{array}{l}23 \text { Nov } \\
2016\end{array}$ & $\begin{array}{l}\text { Erasmus } \\
\text { Medical Center }\end{array}$ & $\begin{array}{l}\text { Erasmus Medical } \\
\text { Center }\end{array}$ & $\begin{array}{c}\text { Poen,MJ, Van Der } \\
\text { Jeugd,HP, Vuong,0, } \\
\text { Scheuer,RD, Fouchier,RAM } \\
\text { et al. }\end{array}$ \\
\hline $\begin{array}{l}\text { EPI_- } \\
\text { ISL_269600 }\end{array}$ & A/Great_Crested_Grebe/Netherlands/2/2016 & $\begin{array}{l}21 \mathrm{Dec} \\
2016\end{array}$ & $\begin{array}{c}\text { Erasmus } \\
\text { Medical Center }\end{array}$ & $\begin{array}{l}\text { Erasmus Medical } \\
\text { Center }\end{array}$ & $\begin{array}{c}\text { Poen,MJ, Van Der } \\
\text { Jeugd,HP, Vuong, } 0 \text {, } \\
\text { Scheuer,RD, Fouchier,RAM } \\
\text { et al. }\end{array}$ \\
\hline $\begin{array}{l}\text { EPI_- } \\
\text { ISL_269696 }\end{array}$ & A/Eurasian_Wigeon/Netherlands/23/2016 & $\begin{array}{l}05 \mathrm{Dec} \\
2016\end{array}$ & $\begin{array}{l}\text { Erasmus } \\
\text { Medical Center }\end{array}$ & $\begin{array}{l}\text { Erasmus Medical } \\
\text { Center }\end{array}$ & $\begin{array}{c}\text { Poen,MJ, Van Der } \\
\text { Jeugd,HP, Vuong,O, } \\
\text { Scheuer,RD, Fouchier,RAM } \\
\text { et al. }\end{array}$ \\
\hline $\begin{array}{l}\text { EPI_- } \\
\text { ISL_269694 }\end{array}$ & A/Eurasian_Wigeon/Netherlands/1/2016 & $\begin{array}{l}04 \mathrm{Dec} \\
2016\end{array}$ & $\begin{array}{c}\text { Erasmus } \\
\text { Medical Center }\end{array}$ & $\begin{array}{c}\text { Erasmus Medical } \\
\text { Center }\end{array}$ & $\begin{array}{c}\text { Poen,MJ,Müskens,G.J.D.M, } \\
\text { Vuong,O, Scheuer,RD, } \\
\text { Fouchier,RAM et al. }\end{array}$ \\
\hline $\begin{array}{l}\text { EPI_ } \\
\text { ISL_269596 }\end{array}$ & A/Eurasian_Wigeon/Netherlands/13/2016 & $\begin{array}{l}14 \mathrm{Dec} \\
2016\end{array}$ & $\begin{array}{c}\text { Erasmus } \\
\text { Medical Center }\end{array}$ & $\begin{array}{l}\text { Erasmus Medical } \\
\text { Center }\end{array}$ & $\begin{array}{c}\text { Poen,MJ, Van Der } \\
\text { Jeugd,HP, Vuong,O, } \\
\text { Scheuer,RD, Fouchier, RAM } \\
\text { et al. }\end{array}$ \\
\hline $\begin{array}{l}\text { EPI_- } \\
\text { ISL_269595 }\end{array}$ & A/Eurasian_Wigeon/Netherlands/12/2016 & $\begin{array}{l}14 \mathrm{Dec} \\
2016\end{array}$ & $\begin{array}{c}\text { Erasmus } \\
\text { Medical Center }\end{array}$ & $\begin{array}{c}\text { Erasmus Medical } \\
\text { Center }\end{array}$ & $\begin{array}{c}\text { Poen,MJ, Van Der } \\
\text { Jeugd,HP, Vuong, } 0 \text {, } \\
\text { Scheuer,RD, Fouchier,RAM } \\
\text { et al. }\end{array}$ \\
\hline $\begin{array}{l}\text { EPI_ } \\
\text { ISL_269594 }\end{array}$ & A/Eurasian_Wigeon/Netherlands/22/2016 & $\begin{array}{l}14 \mathrm{Dec} \\
2016\end{array}$ & $\begin{array}{c}\text { Erasmus } \\
\text { Medical Center }\end{array}$ & $\begin{array}{c}\text { Erasmus Medical } \\
\text { Center }\end{array}$ & $\begin{array}{c}\text { Poen,MJ, Van Der } \\
\text { Jeugd,HP, Vuong,O, } \\
\text { Scheuer,RD, Fouchier,RAM } \\
\text { et al. }\end{array}$ \\
\hline $\begin{array}{l}\text { EPI_- } \\
\text { ISL_269593 }\end{array}$ & A/Eurasian_Wigeon/Netherlands/11/2016 & $\begin{array}{l}13 \mathrm{Dec} \\
2016\end{array}$ & $\begin{array}{c}\text { Erasmus } \\
\text { Medical Center }\end{array}$ & $\begin{array}{c}\text { Erasmus Medical } \\
\text { Center }\end{array}$ & $\begin{array}{c}\text { Poen, MJ, Van Der } \\
\text { Jeugd,HP, Vuong,O, } \\
\text { Scheuer, RD, Fouchier,RAM } \\
\text { et al. }\end{array}$ \\
\hline $\begin{array}{l}\text { EPI_ } \\
\text { ISL_269592 }\end{array}$ & A/Eurasian_Wigeon/Netherlands/8/2016 & $\begin{array}{l}09 \mathrm{Dec} \\
2016\end{array}$ & $\begin{array}{c}\text { Erasmus } \\
\text { Medical Center }\end{array}$ & $\begin{array}{c}\text { Erasmus Medical } \\
\text { Center }\end{array}$ & $\begin{array}{c}\text { Poen,MJ, Van Der } \\
\text { Jeugd,HP, Vuong,O, } \\
\text { Scheuer,RD, Fouchier,RAM } \\
\text { et al. }\end{array}$ \\
\hline $\begin{array}{l}\text { EPI_ } \\
\text { ISL_269591 }\end{array}$ & A/Eurasian_Wigeon/Netherlands/6/2016 & $\begin{array}{l}09 \mathrm{Dec} \\
2016\end{array}$ & $\begin{array}{c}\text { Erasmus } \\
\text { Medical Center }\end{array}$ & $\begin{array}{c}\text { Erasmus Medical } \\
\text { Center }\end{array}$ & $\begin{array}{c}\text { Poen,MJ, Van Der } \\
\text { Jeugd,HP, Vuong,O, } \\
\text { Scheuer,RD, Fouchier,RAM } \\
\text { et al. }\end{array}$ \\
\hline
\end{tabular}


Acknowledgements of authors, and originating and submitting laboratories providing the sequences used for phylogenetic analysis

\begin{tabular}{|c|c|c|c|c|c|}
\hline Isolate ID & Isolates name & $\begin{array}{l}\text { Collection } \\
\text { date }\end{array}$ & $\begin{array}{l}\text { Originating } \\
\text { laboratory }\end{array}$ & $\begin{array}{l}\text { Submitting } \\
\text { Laboratory }\end{array}$ & Authors \\
\hline $\begin{array}{l}\text { EPI_- } \\
\text { ISL_268937 }\end{array}$ & A/Eurasian_Wigeon/Netherlands/10/2016 & $\begin{array}{l}08 \mathrm{Dec} \\
2016\end{array}$ & $\begin{array}{c}\text { Erasmus } \\
\text { Medical Center }\end{array}$ & $\begin{array}{c}\text { Erasmus Medical } \\
\text { Center }\end{array}$ & $\begin{array}{c}\text { Poen, MJ, Van Der } \\
\text { Jeugd,HP, Vuong,O, } \\
\text { Scheuer,RD, Fouchier, RAM } \\
\text { et al. }\end{array}$ \\
\hline $\begin{array}{l}\text { EPI_ } \\
\text { ISL_255914 }\end{array}$ & A/Eurasian Wigeon/Netherlands/9/2016 & $\begin{array}{l}04 \mathrm{Dec} \\
2016\end{array}$ & $\begin{array}{c}\text { Erasmus } \\
\text { Medical Center }\end{array}$ & $\begin{array}{c}\text { Erasmus Medical } \\
\text { Center }\end{array}$ & $\begin{array}{c}\text { Poen,MJ, Van Der } \\
\text { Jeugd,HP, Vuong, } 0 \text {, } \\
\text { Scheuer,RD, Fouchier, RAM } \\
\text { et al. }\end{array}$ \\
\hline $\begin{array}{l}\text { EPI_ } \\
\text { ISL_255912 }\end{array}$ & A/Eurasian Wigeon/Netherlands/4/2016 & $\begin{array}{c}09 \mathrm{Dec} \\
2016\end{array}$ & $\begin{array}{c}\text { Erasmus } \\
\text { Medical Center }\end{array}$ & $\begin{array}{c}\text { Erasmus Medical } \\
\text { Center }\end{array}$ & $\begin{array}{c}\text { Poen, MJ, Van Der } \\
\text { Jeugd,HP, Vuong,0, } \\
\text { Scheuer,RD, Fouchier,RAM } \\
\text { et al. }\end{array}$ \\
\hline $\begin{array}{l}\text { EPI_ } \\
\text { ISL_269703 }\end{array}$ & A/Eurasian_Wigeon/Netherlands/25/2016 & $\begin{array}{l}05 \mathrm{Dec} \\
2016\end{array}$ & $\begin{array}{c}\text { Erasmus } \\
\text { Medical Center }\end{array}$ & $\begin{array}{c}\text { Erasmus Medical } \\
\text { Center }\end{array}$ & $\begin{array}{c}\text { Poen, MJ, Van Der } \\
\text { Jeugd,HP, Vuong,0, } \\
\text { Scheuer,RD, Fouchier,RAM } \\
\text { et al. }\end{array}$ \\
\hline $\begin{array}{l}\text { EPI__ } \\
\text { ISL_269695 }\end{array}$ & A/Eurasian_Wigeon/Netherlands/21/2016 & $\begin{array}{l}05 \mathrm{Dec} \\
2016\end{array}$ & $\begin{array}{c}\text { Erasmus } \\
\text { Medical Center }\end{array}$ & $\begin{array}{c}\text { Erasmus Medical } \\
\text { Center }\end{array}$ & $\begin{array}{c}\text { Poen, MJ, Van Der } \\
\text { Jeugd,HP, Vuong,0, } \\
\text { Scheuer,RD, Fouchier,RAM } \\
\text { et al. }\end{array}$ \\
\hline $\begin{array}{l}\text { EPI_- } \\
\text { ISL_269692 }\end{array}$ & A/Mallard/Netherlands/3/2017 & 11 Jan 2017 & $\begin{array}{c}\text { Erasmus } \\
\text { Medical Center }\end{array}$ & $\begin{array}{c}\text { Erasmus Medical } \\
\text { Center }\end{array}$ & $\begin{array}{c}\text { Poen, MJ, Van Der } \\
\text { Jeugd,HP, Vuong,O, } \\
\text { Scheuer,RD, Fouchier,RAM } \\
\text { et al. }\end{array}$ \\
\hline $\begin{array}{l}\text { EPI_- } \\
\text { ISL_269604 }\end{array}$ & A/Mallard/Netherlands/1/2017 & $\begin{array}{l}07 \text { Jan } \\
2017\end{array}$ & $\begin{array}{c}\text { Erasmus } \\
\text { Medical Center }\end{array}$ & $\begin{array}{c}\text { Erasmus Medical } \\
\text { Center }\end{array}$ & $\begin{array}{c}\text { Poen, MJ, Van Der } \\
\text { Jeugd,HP, Vuong,O, } \\
\text { Scheuer,RD, Fouchier,RAM } \\
\text { et al. }\end{array}$ \\
\hline $\begin{array}{l}\text { EPI_- } \\
\text { ISL_269603 }\end{array}$ & A/Mallard/Netherlands/51/2016 & $\begin{array}{c}20 \mathrm{Dec} \\
2016\end{array}$ & $\begin{array}{c}\text { Erasmus } \\
\text { Medical Center }\end{array}$ & $\begin{array}{c}\text { Erasmus Medical } \\
\text { Center }\end{array}$ & $\begin{array}{c}\text { Poen, MJ, Van Der } \\
\text { Jeugd,HP, Vuong,O, } \\
\text { Scheuer,RD, Fouchier,RAM } \\
\text { et al. }\end{array}$ \\
\hline $\begin{array}{l}\text { EPI_ } \\
\text { ISL_255913 }\end{array}$ & A/Mallard/Netherlands/2/2017 & $\begin{array}{l}07 \text { Jan } \\
2017\end{array}$ & $\begin{array}{c}\text { Erasmus } \\
\text { Medical Center }\end{array}$ & $\begin{array}{c}\text { Erasmus Medical } \\
\text { Center }\end{array}$ & $\begin{array}{c}\text { Poen,MJ, Van Der } \\
\text { Jeugd,HP, Vuong,O, } \\
\text { Scheuer,RD, Fouchier,RAM } \\
\text { et al. }\end{array}$ \\
\hline $\begin{array}{l}\text { EPI_ } \\
\text { ISL_268927 }\end{array}$ & A/Common_Buzzard/Netherlands/1/2016 & $\begin{array}{l}07 \mathrm{Dec} \\
2016\end{array}$ & $\begin{array}{c}\text { Erasmus } \\
\text { Medical Center }\end{array}$ & $\begin{array}{c}\text { Erasmus Medical } \\
\text { Center }\end{array}$ & $\begin{array}{c}\text { Poen, MJ, Van Der } \\
\text { Jeugd,HP, Vuong,0, } \\
\text { Scheuer,RD, Fouchier,RAM } \\
\text { et al. }\end{array}$ \\
\hline $\begin{array}{l}\text { EPI_ } \\
\text { ISL_255891 }\end{array}$ & A/Tufted Duck/Netherlands/1/2016 & $\begin{array}{l}25 \text { Nov } \\
2016\end{array}$ & $\begin{array}{c}\text { Erasmus } \\
\text { Medical Center }\end{array}$ & $\begin{array}{c}\text { Erasmus Medical } \\
\text { Center }\end{array}$ & $\begin{array}{c}\text { Poen,MJ, Van Der } \\
\text { Jeugd,HP, Vuong,O, } \\
\text { Scheuer,RD, Fouchier,RAM } \\
\text { et al. }\end{array}$ \\
\hline $\begin{array}{l}\text { EPI_ } \\
\text { ISL_268866 }\end{array}$ & A/Back-headed_Gull/Netherlands/9/2016 & $\begin{array}{l}20 \mathrm{Dec} \\
2016\end{array}$ & $\begin{array}{c}\text { Erasmus } \\
\text { Medical Center }\end{array}$ & $\begin{array}{c}\text { Erasmus Medical } \\
\text { Center }\end{array}$ & $\begin{array}{c}\text { Poen, MJ, Van Der } \\
\text { Jeugd,HP, Vuong,0, } \\
\text { Scheuer,RD, Fouchier,RAM } \\
\text { et al. }\end{array}$ \\
\hline $\begin{array}{l}\text { EPI_- } \\
\text { ISL_268800 }\end{array}$ & A/Black-headed_Gull/Netherlands/17/2016 & $\begin{array}{l}20 \mathrm{Dec} \\
2016\end{array}$ & $\begin{array}{c}\text { Erasmus } \\
\text { Medical Center }\end{array}$ & $\begin{array}{c}\text { Erasmus Medical } \\
\text { Center }\end{array}$ & $\begin{array}{c}\text { Poen,MJ, Van Der } \\
\text { Jeugd,HP, Vuong,O, } \\
\text { Scheuer,RD, Fouchier,RAM } \\
\text { et al. }\end{array}$ \\
\hline $\begin{array}{l}\text { EPI_ } \\
\text { ISL_268799 }\end{array}$ & A/Back-headed_Gull/Netherlands/8/2016 & $\begin{array}{l}20 \mathrm{Dec} \\
2016\end{array}$ & $\begin{array}{c}\text { Erasmus } \\
\text { Medical Center }\end{array}$ & $\begin{array}{c}\text { Erasmus Medical } \\
\text { Center }\end{array}$ & $\begin{array}{c}\text { Poen,MJ, Van Der } \\
\text { Jeugd,HP, Vuong,O, } \\
\text { Scheuer,RD, Fouchier,RAM } \\
\text { et al. }\end{array}$ \\
\hline $\begin{array}{l}\text { EPI_ } \\
\text { ISL_268929 }\end{array}$ & A/Common_Eider/Netherlands/2/2016 & $\begin{array}{l}20 \mathrm{Dec} \\
2016\end{array}$ & $\begin{array}{c}\text { Erasmus } \\
\text { Medical Center }\end{array}$ & $\begin{array}{c}\text { Erasmus Medical } \\
\text { Center }\end{array}$ & $\begin{array}{c}\text { Poen,MJ, Van Der } \\
\text { Jeugd,HP, Vuong,O, } \\
\text { Scheuer,RD, Fouchier,RAM } \\
\text { et al. }\end{array}$ \\
\hline $\begin{array}{l}\text { EPI_ } \\
\text { ISL_269693 }\end{array}$ & A/Common_Pochard/Netherlands/1/2016 & $\begin{array}{l}25 \text { Nov } \\
2016\end{array}$ & $\begin{array}{c}\text { Erasmus } \\
\text { Medical Center }\end{array}$ & $\begin{array}{c}\text { Erasmus Medical } \\
\text { Center }\end{array}$ & $\begin{array}{c}\text { Poen,MJ, Van Der } \\
\text { Jeugd,HP, Vuong,0, } \\
\text { Scheuer,RD, Fouchier,RAM } \\
\text { et al. }\end{array}$ \\
\hline
\end{tabular}


TABLE 2A

Wild bird species sampled for virus detection in the Netherlands before and during the second wave of highly pathogenic avian influenza H5N8 virus in Europe and results of virological assays, February 2016-March $2017(\mathrm{n}=10,726)$

\begin{tabular}{|c|c|c|c|c|c|c|c|c|c|c|c|c|c|c|}
\hline \multirow[b]{3}{*}{ Order } & \multirow[b]{3}{*}{ Family } & \multirow[b]{3}{*}{ Species } & \multirow{2}{*}{\multicolumn{4}{|c|}{$\begin{array}{c}1 \text { February 2016-7 November } 2016 \\
\text { Alive without clinical signs }\end{array}$}} & \multicolumn{8}{|c|}{8 November 2016-31 March 2017} \\
\hline & & & & & & & \multicolumn{4}{|c|}{ Alive without clinical signs } & \multicolumn{4}{|c|}{$\begin{array}{l}\text { Found dead } \\
\text { F }\end{array}$} \\
\hline & & & $\begin{array}{l}\text { Number } \\
\text { of birds } \\
\text { Sampled }\end{array}$ & $\begin{array}{c}\text { Number } \\
\text { of birds } \\
\text { Alv } \\
\text { positive }\end{array}$ & $\begin{array}{c}\text { Number } \\
\text { of birds } \\
\mathrm{H}_{5} \\
\text { positive }\end{array}$ & Pathotype & $\begin{array}{l}\text { Number } \\
\text { of birds } \\
\text { sampled }\end{array}$ & $\begin{array}{c}\text { Number } \\
\text { of birds } \\
\text { Alv } \\
\text { positive }\end{array}$ & $\begin{array}{c}\text { Number } \\
\text { of birds } \\
\mathrm{H}_{5} \\
\text { positive }\end{array}$ & Pathotype & $\begin{array}{l}\text { Number } \\
\text { of birds } \\
\text { sampled }\end{array}$ & $\begin{array}{c}\text { Number } \\
\text { of birds } \\
\text { Alv } \\
\text { positive }\end{array}$ & $\begin{array}{c}\text { Number } \\
\text { of birds } \\
\mathrm{H}_{5} \\
\text { positive }\end{array}$ & Pathotype \\
\hline \multirow{22}{*}{ Anseriformes } & \multirow{14}{*}{ Ducks } & $\begin{array}{l}\text { Common eider } \\
\text { (Somateria } \\
\text { mollissima) }\end{array}$ & 0 & o & o & NA & o & o & o & NA & 1 & 1 & 1 & $1 \mathrm{x} \mathrm{HPAI}$ \\
\hline & & $\begin{array}{l}\text { Common pochard } \\
\text { (Aythya ferina) }\end{array}$ & o & o & o & NA & o & o & o & NA & 1 & 1 & 1 & n.i. \\
\hline & & $\begin{array}{l}\text { Common shelduck } \\
\text { (Tadorna tadorna) }\end{array}$ & 2 & o & o & NA & o & o & o & NA & o & 0 & o & NA \\
\hline & & $\begin{array}{c}\text { Domestic duck } \\
\text { (Anas } \\
\text { platyrhynchos } \\
\text { domesticus) }\end{array}$ & o & o & o & NA & 1 & o & o & NA & o & 0 & o & NA \\
\hline & & $\begin{array}{c}\text { Egyptian goose } \\
\text { (Alopochen } \\
\text { aegyptiaca) }\end{array}$ & 30 & o & o & NA & 17 & o & 0 & NA & 0 & 0 & 0 & NA \\
\hline & & $\begin{array}{l}\text { Eurasian teal } \\
\text { (Anas crecca) }\end{array}$ & 46 & 21 & 0 & NA & 42 & 5 & 1 & $1 \times$ LPAI & 0 & 0 & 0 & NA \\
\hline & & $\begin{array}{l}\text { Eurasian wigeon } \\
\text { (Anas penelope) }\end{array}$ & 639 & 339 & 10 & $\underset{\text { LPAI }}{\text { 6xn.i., }}$ & 2,634 & 118 & 37 & $\begin{array}{l}\text { 14x HPAl, } \\
23 \times \text { n.i. }\end{array}$ & 7 & 7 & 7 & $7 \times \mathrm{HPAl}$ \\
\hline & & $\begin{array}{c}\text { Gadwall } \\
\text { (Anas strepera) }\end{array}$ & 131 & 65 & 0 & NA & 11 & 1 & 1 & $1 \times$ n.i. & 1 & 1 & 0 & NA \\
\hline & & $\begin{array}{c}\text { Garganey } \\
\text { (Anas querquedula) }\end{array}$ & 2 & 2 & 0 & NA & 0 & & & NA & 0 & 0 & 0 & NA \\
\hline & & $\begin{array}{l}\text { Greater scaup } \\
\text { (Aythya marila) }\end{array}$ & 1 & o & 0 & NA & 2 & 1 & 0 & NA & o & 0 & 0 & NA \\
\hline & & $\begin{array}{c}\text { Mallard } \\
\text { (Anas } \\
\text { platyrhynchos) }\end{array}$ & 3,169 & 555 & 20 & $\begin{array}{l}\text { 4x n.i., } \\
\text { 16x LPAI }\end{array}$ & 1,824 & 338 & 78 & $\begin{array}{l}\text { 17x HPAI, } \\
5 \times \text { LPAI, } \\
56 \times \text { n.i. }\end{array}$ & 3 & 3 & 2 & $2 x \mathrm{HPAI}$ \\
\hline & & $\begin{array}{l}\text { Northern pintail } \\
\text { (Anas acuta) }\end{array}$ & 12 & 9 & 0 & NA & 6 & 0 & 0 & NA & 0 & 0 & 0 & NA \\
\hline & & $\begin{array}{l}\text { Northern shoveler } \\
\text { (Anas clypeata) }\end{array}$ & 14 & 4 & 0 & NA & 3 & 0 & 0 & NA & 0 & 0 & 0 & NA \\
\hline & & $\begin{array}{c}\text { Tufted duck } \\
\text { (Aythya fuligula) }\end{array}$ & 2 & 1 & 0 & NA & 2 & o & o & NA & 1 & 1 & 1 & $1 \mathrm{xPAI}$ \\
\hline & \multirow{5}{*}{ Geese } & $\begin{array}{l}\text { Barnacle goose } \\
\text { (Branta leucopsis) }\end{array}$ & 589 & o & 0 & NA & o & & & NA & o & 0 & 0 & NA \\
\hline & & $\begin{array}{c}\text { Bean goose } \\
\text { (Anser fabalis) }\end{array}$ & 0 & 0 & 0 & NA & 1 & 0 & 0 & NA & o & 0 & 0 & NA \\
\hline & & $\begin{array}{c}\text { Canada goose } \\
\text { (Branta canadensis) }\end{array}$ & 23 & 0 & 0 & NA & 3 & o & o & NA & o & 0 & 0 & NA \\
\hline & & $\begin{array}{c}\text { Great white-fronted } \\
\text { goose } \\
\text { (Anser albifrons) }\end{array}$ & 27 & o & o & NA & 40 & o & o & NA & o & 0 & 0 & NA \\
\hline & & $\begin{array}{l}\text { Greylag goose } \\
\text { (Anser anser) }\end{array}$ & 310 & 3 & 1 & $1 \times$ LPAI & o & & & NA & o & o & 0 & NA \\
\hline & \multirow{3}{*}{ Swans } & $\begin{array}{l}\text { Bewick's swan } \\
\text { (Cygnus } \\
\text { columbianus } \\
\text { bewickii) }\end{array}$ & 0 & o & 0 & NA & 92 & 3 & o & NA & o & o & 0 & NA \\
\hline & & $\begin{array}{l}\text { Mute swan } \\
\text { (Cygnus olor) }\end{array}$ & 0 & 0 & 0 & NA & 36 & 0 & 0 & NA & 0 & 0 & 0 & NA \\
\hline & & $\begin{array}{l}\text { Whooper swan } \\
\text { (Cygnus cygnus) }\end{array}$ & 0 & 0 & 0 & NA & 3 & o & o & NA & o & 0 & 0 & NA \\
\hline
\end{tabular}




\section{TABLE 2B}

Wild bird species sampled for virus detection in the Netherlands before and during the second wave of highly pathogenic avian influenza H5N8 virus in Europe and results of virological assays, February 2016-March 2017 (n = 10,726)

\begin{tabular}{|c|c|c|c|c|c|c|c|c|c|c|c|c|c|c|}
\hline \multirow[b]{3}{*}{ Order } & \multirow[b]{3}{*}{ Family } & \multirow[b]{3}{*}{ Species } & \multirow{2}{*}{\multicolumn{4}{|c|}{$\begin{array}{c}1 \text { February } 2016-7 \text { November } 2016 \\
\text { Alive without clinical signs }\end{array}$}} & \multicolumn{8}{|c|}{8 November 2016-31 March 2017} \\
\hline & & & & & & & \multicolumn{4}{|c|}{ Alive without clinical signs } & \multicolumn{4}{|c|}{ Found dead } \\
\hline & & & $\begin{array}{l}\text { Number } \\
\text { of birds } \\
\text { Sampled }\end{array}$ & 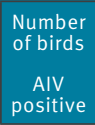 & \begin{tabular}{|c|} 
Number \\
of birds \\
$\mathrm{H}_{5}$ \\
positive
\end{tabular} & Pathotype & $\begin{array}{l}\text { Number } \\
\text { of birds } \\
\text { sampled }\end{array}$ & $\begin{array}{c}\text { Number } \\
\text { of birds } \\
\text { Alv } \\
\text { positive }\end{array}$ & $\begin{array}{c}\text { Number } \\
\text { of birds } \\
\mathrm{H}_{5} \\
\text { positive }\end{array}$ & Pathotype & $\begin{array}{l}\text { Number } \\
\text { of birds } \\
\text { sampled }\end{array}$ & \begin{tabular}{|c|}
$\begin{array}{c}\text { Number } \\
\text { of birds } \\
\text { Alv } \\
\text { positive }\end{array}$ \\
\end{tabular} & $\begin{array}{c}\text { Number } \\
\text { of birds } \\
\mathrm{H}_{5} \\
\text { positive }\end{array}$ & Pathotype \\
\hline \multirow{7}{*}{ Charadriiformes } & \multirow{7}{*}{ Gulls } & $\begin{array}{l}\text { Black-headed gull } \\
\text { (Chroicocephalus } \\
\text { ridibundus) }\end{array}$ & 432 & 59 & o & NA & 287 & 2 & 0 & NA & 4 & 4 & 3 & $3 \times \mathrm{HPAl}$ \\
\hline & & $\begin{array}{c}\text { Caspian gull } \\
\text { (Larus cachinnans) }\end{array}$ & o & o & o & NA & 1 & o & o & NA & 1 & 1 & o & NA \\
\hline & & $\begin{array}{l}\text { Eurasian herring } \\
\text { gull } \\
\text { (Larus argentatus) }\end{array}$ & 24 & o & o & NA & 20 & 1 & o & NA & 2 & 2 & 2 & $\begin{array}{c}1 \times \mathrm{HPAl}, \\
1 \times \mathrm{n} . \mathrm{i} .\end{array}$ \\
\hline & & $\begin{array}{c}\text { Great black- } \\
\text { backed gull } \\
\text { (Larus marinus) }\end{array}$ & o & 0 & o & NA & o & o & o & NA & 8 & 8 & 5 & $5 \times \mathrm{HPAI}$ \\
\hline & & $\begin{array}{l}\text { Lesser black- } \\
\text { backed gull } \\
\text { (Larus fuscus) }\end{array}$ & 66 & o & o & NA & o & o & o & NA & 1 & 1 & 1 & 1x HPAI \\
\hline & & $\begin{array}{c}\text { Mew gull } \\
\text { (Larus canus) }\end{array}$ & 2 & o & 0 & NA & 13 & o & o & NA & 1 & 1 & 1 & 1x HPAI \\
\hline & & $\begin{array}{l}\text { Yellow-legged gull } \\
\text { (Larus michahellis) }\end{array}$ & o & o & o & NA & o & o & 0 & NA & 1 & o & 0 & NA \\
\hline \multirow{3}{*}{ Gruiformes } & \multirow{3}{*}{ Coots } & $\begin{array}{c}\text { Common coot } \\
\text { (Fulica atra) }\end{array}$ & 2 & o & 0 & NA & 100 & o & 0 & NA & o & o & 0 & NA \\
\hline & & $\begin{array}{l}\text { Common moorhen } \\
\text { (Gallinula } \\
\text { chloropus) }\end{array}$ & o & o & o & NA & 4 & o & 0 & NA & o & o & o & NA \\
\hline & & $\begin{array}{c}\text { Water rail } \\
\text { (Rallus aquaticus) }\end{array}$ & o & 0 & o & NA & 20 & o & o & NA & o & o & o & NA \\
\hline Pelicaniformes & Ardeidae & $\begin{array}{c}\text { Grey heron } \\
\text { (Ardea cinerea) }\end{array}$ & 0 & o & o & NA & 3 & o & 0 & NA & o & o & o & NA \\
\hline Podicipediformes & Grebes & $\begin{array}{l}\text { Great crested } \\
\text { grebe } \\
\text { (Podiceps } \\
\text { cristatus) }\end{array}$ & 0 & 0 & o & NA & o & o & o & NA & 1 & 1 & 1 & $1 \mathrm{x} \mathrm{HPAI}$ \\
\hline Suliformes & Cormorants & $\begin{array}{c}\text { Great cormorant } \\
\text { (Phalacrocorax } \\
\text { carbo) }\end{array}$ & o & o & o & NA & o & o & o & NA & 1 & o & 0 & NA \\
\hline Passeriformes & Corvidae & $\begin{array}{c}\text { Eurasian magpie } \\
\text { (Pica pica) }\end{array}$ & o & o & o & NA & 1 & o & o & NA & o & o & o & NA \\
\hline Falconiformes & Falcons & $\begin{array}{l}\text { Peregrine falcon } \\
\text { (Falco peregrinus) }\end{array}$ & o & 0 & o & NA & o & o & o & NA & 1 & 1 & 1 & 1x HPAI \\
\hline Accipitriformes & Accipitridae & $\begin{array}{c}\text { Common buzzard } \\
\text { (Buteo buteo) }\end{array}$ & o & o & o & NA & 1 & 1 & 1 & $1 \times \mathrm{HPAl}$ & 1 & 1 & 1 & $1 \times \mathrm{HPAl}$ \\
\hline Total & NA & NA & 5,523 & 1,058 & 31 & NA & 5,167 & 470 & 118 & $32 \times \mathrm{HPAI}$ & 36 & 34 & 27 & $25 \times \mathrm{HPAI}$ \\
\hline
\end{tabular}

AIV: avian influenza virus; HPAI: highly pathogenic avian influenza; LPAI: low pathogenic avian influenza; NA: not applicable; n.i.: not identifiable because of low virus load.

Maximum likelihood (ML) phylogenetic trees were constructed based on the HA (1,637 nt: position 49-1,685) and NA (1,227 nt: position 64-1,291) genes. ML trees were generated using PhyML version 3.1 using the general time-reversible (GTR) model, performing subtree pruning and regrafting (SPR) searches [20]. The reliability of the phylogenetic grouping was assessed with 250 bootstrap replicates. Trees were visualised using Figtree version 1.4.3 (http://tree.bio.ed.ac.uk/ software/figtree). ML trees of HA and NA were used in Dendroscope version 3.5.9 (http://dendroscope.org/) [21] to display a tanglegram between the HA and NA midpoint rooted phylogenies. The twines were colourcoded according to wave and location.

\section{Antibody detection}

Serum samples were initially screened for the presence of clade 2.3.4.4 $\mathrm{H}_{5}(\mathrm{~N} 8)$-specific (A/Chicken/ 


\section{TABLE 3}

Wild bird species sampled in the Netherlands for antibody detection in response to the second wave of highly pathogenic avian influenza (HPAI) H5N8 virus in Europe, 2016/2017 $(n=459)$ and those showing HPAI H5 clade 2.3.4.4-specific antibodies $(\mathrm{n}=20)$ based on repeated haemagglutination inhibition assays $(\mathrm{HI})$, March 2016-February 2017

\begin{tabular}{|c|c|c|c|c|c|c|c|c|}
\hline \multirow{3}{*}{ Order } & \multirow{3}{*}{ Family } & \multirow{3}{*}{ Species } & \multicolumn{6}{|c|}{ Number of individuals } \\
\hline & & & \multicolumn{2}{|c|}{1 March 2016} & \multicolumn{2}{|c|}{23 October 2016} & \multicolumn{2}{|c|}{$\begin{array}{l}13 \text { November } 2016-8 \\
\text { February } 2017\end{array}$} \\
\hline & & & Tested & $\begin{array}{c}\mathrm{H}_{5} \text { clade } \\
2.3 \cdot 4^{-} 4^{-} \\
\text {specific } \\
\text { antibodies }\end{array}$ & Tested & $\begin{array}{c}\mathrm{H}_{5} \text { clade } \\
2.3 \cdot 4 \cdot 4^{-} \\
\text {specific } \\
\text { antibodies }\end{array}$ & Tested & $\begin{array}{c}\mathrm{H}_{5} \text { clade } \\
2.3 \cdot 4 \cdot 4^{-} \\
\text {specific } \\
\text { antibodies }\end{array}$ \\
\hline \multirow{10}{*}{ Anseriformes } & \multirow{7}{*}{ Ducks } & Egyptian goose (Alopochen aegyptiaca) & 0 & 0 & 0 & 0 & 10 & 0 \\
\hline & & Eurasian teal (Anas crecca) & 0 & 0 & 0 & o & 22 & 0 \\
\hline & & Eurasian wigeon (Anas penelope) & 28 & 2 & 41 & 1 & 63 & 2 \\
\hline & & Gadwall (Anas strepera) & 0 & 0 & 0 & 0 & 5 & 0 \\
\hline & & Mallard (Anas platyrhynchos) & 0 & 0 & 0 & o & 72 & 11 \\
\hline & & Northern pintail (Anas acuta) & 0 & 0 & 0 & 0 & 6 & 0 \\
\hline & & Tufted duck (Aythya fuligula) & 0 & 0 & 0 & 0 & 1 & 0 \\
\hline & \multirow{3}{*}{ Swans } & $\begin{array}{c}\text { Bewick's swan (Cygnus columbianus } \\
\text { bewickii) }\end{array}$ & 0 & 0 & 0 & 0 & 20 & 0 \\
\hline & & Mute swan (Cygnus olor) & 0 & 0 & 0 & 0 & 24 & 3 \\
\hline & & Whooper swan (Cygnus cygnus) & 0 & 0 & 0 & 0 & 3 & 0 \\
\hline \multirow{4}{*}{ Charadriiformes } & \multirow{4}{*}{ Gulls } & $\begin{array}{l}\text { Black-headed gull (Chroicocephalus } \\
\text { ridibundus) }\end{array}$ & 0 & 0 & 0 & 0 & 88 & 1 \\
\hline & & Caspian gull (Larus cachinnans) & 0 & 0 & 0 & 0 & 1 & 0 \\
\hline & & Eurasian herring gull (Larus argentatus) & 0 & 0 & o & 0 & 15 & 0 \\
\hline & & Mew gull (Larus canus) & 0 & 0 & 0 & 0 & 7 & 0 \\
\hline \multirow{2}{*}{ Gruiformes } & \multirow{2}{*}{ Rails } & Common coot (Fulica atra) & 0 & 0 & 0 & 0 & 35 & 0 \\
\hline & & Water rail (Rallus aquaticus) & 0 & 0 & 0 & 0 & 16 & 0 \\
\hline Passeriformes & Corvidae & Eurasian magpie (Pica pica) & 0 & 0 & 0 & 0 & 1 & 0 \\
\hline Pelicaniformes & Ardeidae & Grey heron (Ardea cinerea) & 0 & 0 & 0 & 0 & 1 & 0 \\
\hline Total & NA & NA & 28 & 2 & 41 & 1 & 390 & 17 \\
\hline
\end{tabular}

NA: not applicable.

\section{TABLE 4}

Overview of wild birds or wild birds' droppings, which were sampled in the Netherlands during active surveillance, and positive for highly pathogenic avian influenza H5N8 virus, 23 November 2016-28 January 2017 ( $\mathrm{n}=32$ birds)

\begin{tabular}{|c|c|c|c|c|}
\hline Species & Location & Status & Date & Number of animals \\
\hline Eurasian wigeon & Echtenerburg & Dropping & 23 November 2016 & 1 \\
\hline Eurasian wigeon & Warder & Live without clinical signs & 04 December 2016 & 3 \\
\hline Common buzzard & Hippolytushoef & Live without clinical signs & 07 December 2016 & 1 \\
\hline Eurasian wigeon & Oud Alblas & Live without clinical signs & 08 December 2016 & 1 \\
\hline Eurasian wigeon & Oud Alblas & Live without clinical signs & 12 December 2016 & 1 \\
\hline Eurasian wigeon & Nijkerk & Dropping & 12 December 2016 & 3 \\
\hline Eurasian wigeon & Nijkerk & Dropping & 14 December 2016 & 2 \\
\hline Eurasian wigeon & Nijkerk & Dropping & 21 December 2016 & 3 \\
\hline Mallard & Oud Alblas & Live without clinical signs & 07 January 2017 & 6 \\
\hline Mallard & Oud Alblas & Live without clinical signs & 09 January 2017 & 4 \\
\hline Mallard & Oud Alblas & Live without clinical signs & 10 January 2017 & 2 \\
\hline Mallard & Oud Alblas & Live without clinical signs & 11 January 2017 & 2 \\
\hline Mallard & Oud Alblas & Live without clinical signs & 24 January 2017 & 1 \\
\hline Mallard & Oud Alblas & Live without clinical signs & 25 January 2017 & 1 \\
\hline Mallard & Oud Alblas & Live without clinical signs & 28 January 2017 & 1 \\
\hline
\end{tabular}


TABLE 5

Search results for sequences ${ }^{\text {a }}$ with high similarity to the eight genes found in the full genomes of six highly pathogenic avian influenza H5N8 virus isolates from the Netherlands, 2016/17

\begin{tabular}{|c|c|c|c|}
\hline Gene & BLAST result & Identity & Classification \\
\hline PB2 & [6/6] A/duck/Bangladesh/26920/2015(H3N6) & $>98,7 \%$ & LPAI \\
\hline \multirow{2}{*}{ PB1 } & [5/6] A/chicken/Hunan/S1267/2010(H4N6) & $>97,7 \%$ & LPAI \\
\hline & [1/6] A/duck/Mongolia/179/2015(H3N8) & $97,5 \%$ & LPAI \\
\hline PA & [6/6] A/duck/Mongolia/129/2015 $\left(\mathrm{H}_{3} \mathrm{~N}_{3}\right)$ & $>98,0 \%$ & LPAI \\
\hline HA & [6/6] A/duck/Eastern China/S1109/2014(H5N8) & $>98,7 \%$ & HPAI H5 clade $2 \cdot 3 \cdot 4 \cdot 4$ \\
\hline NP & [6/6] A/Mallard/Netherlands/15/2011(H6N8) & $>99,2 \%$ & LPAI \\
\hline NA & [6/6] A/duck/Eastern China/S1109/2014(H5N8) & $>98,6 \%$ & HPAI H5 clade 2.3.4.4 \\
\hline MP & [6/6] A/duck/Mongolia/179/2015(H3N8) & $>98,1 \%$ & LPAI \\
\hline \multirow{2}{*}{ NS } & [3/6] A/duck/Eastern China/S1109/2014(H5N8) & $>98.8 \%$ & HPAI H5 clade 2.3.4.4 \\
\hline & [3/6] A/goose/Yangzhou/0420/2014(H5N8) & $>97.9 \%$ & HPAI H 5 clade $2 \cdot 3 \cdot 4 \cdot 4$ \\
\hline
\end{tabular}

BLAST: basic local alignment search tool; HA: haemagglutinin; MP: matrix protein; NA: neuraminidase; NP: nucleoprotein; NS: non-structural protein; PA or PB: polymerases (PA, PB2, PB1).

a Searches were carried out using the National Center for Biotechnology Information (NCBI) nucleotide-BLAST.

Netherlands/EMC-3/2014 and A/Great Black-backed Gull/Netherlands/3/2016) and LPAI $\mathrm{H}_{5}\left(\mathrm{~N}_{2}\right)$-specific (A/ Mallard/Netherlands/3/1999) antibodies in a haemagglutination inhibition (HI) assay according to standard procedures $[10,22]$. Due to the generally high non-specific haemagglutination induced by wild bird sera in previous $\mathrm{HI}$ assays [10], all sera were pre-treated with $10 \%$ turkey red blood cells for 1 hour at $4{ }^{\circ} \mathrm{C}$ before analysis. Negative controls, based on incubation of serum without virus, were used to measure non-specific haemagglutination of each serum sample. Serum samples from experimentally inoculated ferrets [23] were used as positive controls.

Serum samples that tested positive for either LPAI $\mathrm{H}_{5} \mathrm{~N}_{2}$ or HPAl $\mathrm{H}_{5}$ clade 2.3.4.4-specific antibodies were further tested in an $\mathrm{HI}$ assay against HPAI viruses of the $\mathrm{H}_{5}$ clades 1 (A/Viet Nam/1194/2004), 2.1 (A/ Indonesia/5/2005), 2.2 (A/Turkey/Turkey/1/2005), and 2.3.4 (A/Anhui/1/2005), and retested against the 2016 clade 2.3.4.4 virus (A/Great Black-backed gull/ Netherlands/3/2016). The viruses used, except the $2016 \mathrm{HPAl} \mathrm{H}_{5} \mathrm{~N} 8$ virus and the LPAI $\mathrm{H}_{5} \mathrm{~N}_{2}$ virus, were recombinant viruses based on an $A / P R / 8 / 34$ virus backbone, containing the HA (without the multi-basic cleavage site) and NA of the representative $\mathrm{H}_{5}$ strains to enable this study within biosafety level 2 laboratories. Assays with the wild type $2016 \mathrm{HPAl} \mathrm{H}_{5} \mathrm{~N} 8$ virus were performed simultaneously in biosafety level 3 conditions.

Subsequently, samples were tested in a virus neutralisation (VN) assay as described previously [10], using titrated virus stocks of the same LPAI $\mathrm{H}_{5} \mathrm{~N}_{2}$ and HPAI $\mathrm{H}_{5}$ clade $1,2.1,2.2,2.3 .4$, and 2016 2.3.4.4 representatives.
Sera were categorised as being either LPAI or HPAI biased or ambiguous, where a bias is defined as a cutoff of $>1 \log _{2}$ differences in titre in $\mathrm{HI}$ assays [24].

\section{Results}

\section{Study population}

Here we report the data of 5,167 wild birds that were tested for the presence of avian influenza viruses between 8 November 2016 and 31 March 2017 in response to the re-introduction of $\mathrm{HPAl} \mathrm{H}_{5} \mathrm{~N} 8$ viruses in the Dutch wild bird population on 8 November 2016 [17]. In addition, we report on all data obtained in our routine active surveillance activities before the first evidence of re-introduction of $\mathrm{HPAl} \mathrm{H}_{5} \mathrm{~N} 8$ virus into the Netherlands, 1 February until 7 November 2016 ( $n=5,523$ ) (Table 2, Figure 1). All birds were caught alive and did not show clinical signs of disease. Also, samples were obtained from 36 birds belonging to 17 species that were sampled post mortem (Table 2).

For antibody detection, serum samples from 459 birds of various species were analysed (Table 3 ). The majority of these samples were obtained between 13 November and 21 December 2016 ( $n=367,18$ species) and on 8 February 2017 ( $\mathrm{n}=23$ mallards (Anas platyrhynchos)). In addition we included blood samples from Eurasian wigeons obtained on 1 March $(n=28)$ and 23 October $2016(n=41)$ that were not analysed previously (Table 3).

Virus detection, isolation and characterisation There was no evidence for the presence of $\mathrm{HPAI}_{5}(\mathrm{~N} 8)$ virus in any of the birds $(n=5,523)$ sampled during routine active surveillance between 1 February and 7 November 2016. In the subsequent period (between 8 November 2016 and 31 March 2017), samples from 145 birds (2.8\%) tested positive for the presence of $\mathrm{H}_{5}$ 


\section{TABLE 6}

Details of the results on low pathogenic (LPAI) H5- and highly pathogenic avian influenza (HPAI) H5 clade 2.3.4.4-specific antibody positive sera using haemagglutination inhibition assays and the resulting HPAI/LPAI bias, Netherlands, 2016/17 $(\mathrm{n}=29)$

\begin{tabular}{|c|c|c|c|c|c|}
\hline Sample ID & Species & Collection date & LPAI & HPAI H5 clade 2.3.4.4 & Bias \\
\hline$C_{320-297}$ & Black-headed gull & 29 November 2016 & $\ll 10$ & 20 & HPAI \\
\hline $320-312$ & Black-headed gull & 05 December 2016 & $\langle 10$ & $20^{a}$ & HPAI \\
\hline $309-9$ & Eurasian wigeon & 01 March 2016 & $\ll 10$ & 20 & HPAI \\
\hline 309-13 & Eurasian wigeon & 01 March 2016 & $\langle 10$ & 10 & Ambiguous \\
\hline $309-23$ & Eurasian wigeon & 01 March 2016 & $\langle 10$ & $20^{\mathrm{a}}$ & HPAI \\
\hline$C_{309-51}$ & Eurasian wigeon & 23 October 2016 & 40 & 40 & Ambiguous \\
\hline $318-57$ & Eurasian wigeon & 04 December 2016 & $\langle 10$ & $10^{\mathrm{a}}$ & Ambiguous \\
\hline $318-63$ & Eurasian wigeon & 04 December 2016 & 40 & 640 & HPAI \\
\hline $318-70$ & Eurasian wigeon & 04 December 2016 & 20 & $\ll 10$ & LPAI \\
\hline $318-75$ & Eurasian wigeon & 04 December 2016 & 10 & 80 & HPAI \\
\hline $320-55$ & Mallard & o9 December 2016 & 320 & 40 & LPAI \\
\hline $314-1813$ & Mallard & 08 February 2017 & $\langle 10$ & 20 & HPAI \\
\hline $314-1815$ & Mallard & 08 February 2017 & 30 & 20 & Ambiguous \\
\hline $314-1817$ & Mallard & 08 February 2017 & 40 & 20 & Ambiguous \\
\hline $314-1819$ & Mallard & 08 February 2017 & $\langle 10$ & 40 & HPAI \\
\hline $314-1820$ & Mallard & 08 February 2017 & 30 & 410 & LPAI \\
\hline $314-1821$ & Mallard & 08 February 2017 & $\ll 10$ & 10 & Ambiguous \\
\hline $314-1823$ & Mallard & 08 February 2017 & 40 & $\ll 10$ & LPAI \\
\hline $314-1824$ & Mallard & 08 February 2017 & $\langle 10$ & 120 & HPAI \\
\hline $314-1825$ & Mallard & 08 February 2017 & 40 & 20 & Ambiguous \\
\hline $314-1826$ & Mallard & 08 February 2017 & 40 & 40 & Ambiguous \\
\hline $314-1827$ & Mallard & 08 February 2017 & 10 & $\langle 10$ & Ambiguous \\
\hline $314-1832$ & Mallard & 08 February 2017 & 10 & 20 & Ambiguous \\
\hline $314-1835$ & Mallard & 08 February 2017 & 30 & 20 & Ambiguous \\
\hline $320-295$ & Mute swan & 05 December 2016 & $\ll 10$ & 30 & HPAI \\
\hline $320-641$ & Mute swan & 07 December 2016 & $\langle 10$ & 30 & HPAI \\
\hline $320-699$ & Mute swan & 14 December 2016 & 30 & $\ll 10$ & LPAI \\
\hline $320-729$ & Mute swan & 15 December 2016 & $\ll 10$ & 20 & $\mathrm{HPAl}$ \\
\hline 320-355 & Whooper Swan & 20 December 2016 & 80 & $\ll 10$ & LPAI \\
\hline
\end{tabular}

HPAI H5 clade 2.3.4.4: highly pathogenic avian influenza A/Great-black backed gull/Netherlands/3/2016 (H5N8); LPAI: low pathogenic avian influenza A/Mallard/Netherlands/3/1999 ( $\left.{ }_{5} \mathrm{~N}_{2}\right)$.

a Titre could not be confirmed in a second haemagglutination inhibition $\mathrm{HI}$ assay.

HA by RRT-PCR. The presence of HPAI H5 clade 2.3.4.4 virus was confirmed in samples of 57 birds (Table 2). Of these, 23 birds (17 mallards, 5 Eurasian wigeons and one common buzzard (Buteo buteo)) were caught and sampled alive without clinical signs, and from nine birds (Eurasian wigeons) fresh droppings were tested positive. (Table 4 ). In total, viruses were isolated in MDCK cells from 48 samples from 33 birds. All cultured viruses belonged to the HPAI $\mathrm{H}_{5} \mathrm{~N} 8$ subtype. The last detection of HPAl clade 2.3.4.4 virus in living birds was in mallards on 28 January 2017. Since then, no additional HPAl clade 2.3.4.4 $\mathrm{H}_{5}$ viruses have been detected in this study.

Virus sequencing and phylogenetic analysis Full length HA and NA sequences of all 48 isolates were obtained by Sanger sequencing. Analysis of these 48 samples showed no differences between sequences obtained from cloacal and oropharyngeal swabs from the same bird, so only one sequence per bird was included in further analyses.

In accordance with previous reports $[11,15,25]$, our phylogenetic analysis (Figure 2) shows a clear distinction for both HA and NA between the 2014/15 group A HPAI $\mathrm{H}_{5} \mathrm{~N} 8$ viruses and the $2016 / 17$ group B viruses. Also, the Russian viruses from May 2016 were distinguishable from the ones that entered eastern European countries (Croatia and Czech Republic) and subsequently more western European counties like Germany and the Netherlands for both HA and NA. The subclade consisting only of Dutch duck and gull viruses might indicate more local virus evolution within the Netherlands. In support, the viruses detected in live mallards in early 
2017 appear as offspring from Eurasian wigeon viruses that were detected 3 weeks earlier and were highly similar to other Dutch viruses that caused mortality in other bird species (Figure 2). However, the number of sequences from other outbreaks in Europe at present is too limited to draw solid conclusions.

Full genome sequences were obtained for six isolates by Sanger sequencing. The six isolates shared 99.1$99.7 \%$ nt sequence identity across all of the eight genes in the genome. Basic local alignment search tool (BLAST, https://www.ncbi.nlm.nih.gov/blast/) search results for earlier detected viruses showed the highest identity (97.8-99.0\%) with the HPAI $\mathrm{H}_{5} \mathrm{~N} 8$ group $\mathrm{B}$ viruses for HA, NA and non-structural protein (NS). The remaining five gene segments (polymerases $\mathrm{PB} 2, \mathrm{~PB} 1$ and PA, nucleoprotein (NP) and matrix protein (MP)) showed the highest identity with Eurasian LPAI viruses (Table 5). New reassortment events were observed for the PA and NP genes since the original detection of the HPAI H5N8 virus in Russia in May 2016.

\section{Influenza A virus $\mathrm{H} 5$-specific antibody \\ detection in wild birds}

Seroreactivity of 459 wild bird sera was determined for different influenza $\mathrm{H}_{5}$ viruses. In a total of 29 sera, antibody titres directed to LPAI $\mathrm{H}_{5}\left(\mathrm{~N}_{2}\right)$ (A/Mallard/ Netherlands/3/1999) or $2016 \mathrm{HPAl} \mathrm{H}_{5}$ clade 2.3.4.4 (A/Great Black-backed Gull/Netherlands/3/2016) or to both of these viruses were detected. There was good correspondence for high reacting sera ( $\mathrm{HI}$ titre $\geq 40$ ) between the $\mathrm{HI}$ antibody titres generated with the 2014 HPAl $\mathrm{H}_{5}$ clade 2.3.4.4 virus and the 2016 virus, suggesting that there has been limited antigenic drift of HPAI $\mathrm{H}_{5} \mathrm{~N} 8$ viruses since 2014. In sera with lower HI titres, there was a strong bias to only react with the $2016 \mathrm{H}_{5}$ clade 2.3.4.4 virus. When the $\mathrm{HI}$ assay for $\mathrm{H}_{5}$ clade $2 \cdot 3 \cdot 4 \cdot 4$-specific antibody positive sera was repeated, all but three titres were reproduced. Of the 10 sera showing antibody titres to both LPAI $\mathrm{H}_{5}$ and HPAl $\mathrm{H}_{5}$ clade 2.3.4.4 virus, one was LPAl-biased, two were HPAl-biased and seven showed ambiguous titres. Overall, $4.2 \%(18 / 431)$ of the sera obtained from October 2016 showed evidence of the presence of HPAl clade 2.3.4.4 $\mathrm{H}_{5}$-specific antibodies based on $\mathrm{HI}$ assays in duplo (Table 6) which was confirmed by VN assays in 14/18 samples from October 2016 onwards and 1/2 from 1 March 2016.

The overall HPAI $\mathrm{H}_{5}$ antibody incidence between October and December 2016 was 2.0\% (8/408). However, in mallards sampled on 8 February 2017 this was $43.5 \%(10 / 23)$ compared with $2.0 \%(1 / 49)$ in mallards sampled between October and December 2016. Comparing the $2016 / 17$ winter with the same seasons in previous years, indicated that mallards and blackheaded gulls (Chroicocephalus ridibundus) first tested positive for $\mathrm{HPAl} \mathrm{H}_{5}$ clade 2.3.4.4-specific antibodies in the 2016/17 winter. In contrast, for Eurasian wigeons, common coots (Fulica atra) and mute swans (Cygnus olor) the detected incidence appeared to be lower in $2016 / 17$ compared to the $2014 / 15$ winter (Table 7). Taking into account all the bird species considered by the surveillance over the different winters, a preliminary incidence of HPAI $\mathrm{H}_{5}$ clade 2.3.4.4.-specific antibodies can be calculated as 0\% before 2014 , rising to $4.6 \%$ during the first outbreak of $\mathrm{HPAl} \mathrm{H}_{5} \mathrm{~N} 8$ virus, decreasing to $3.5 \%$ in the $2015 / 16$ winter and rising to $4.2 \%$ in the $2016 / 17$ winter (Table 7 ).

\section{Discussion}

Here, we report on our virological findings in wild birds during the second wave of European HPAI H5(N8) outbreaks in 2016/17 and further investigate the use of serology in addition to virology in an outbreak situation. In this study we detected HPAI $\mathrm{H}_{5} \mathrm{~N} 8$ viruses in 57 birds of 12 species. Initially, HPAI $\mathrm{H}_{5} \mathrm{~N} 8$ virus was detected in dead wild birds by passive surveillance in mainly tufted ducks and Eurasian wigeons, followed by scavengers [16]. After these die-offs, the virus was detected in live wild birds and shifted from being found mostly Eurasian wigeons early in the outbreak towards mallards later in the outbreak, despite the fact that both species were screened throughout time. Although the number of $\mathrm{HPAI}_{5}(\mathrm{~N} 8)$ infected wild birds identified by passive surveillance in this study and others [16-18] was much higher because of the massive dieoffs and subsequent mandatory testing, the high virus prevalence in mallards would have been missed in passive surveillance studies since hardly any mallards were found dead and infected [16]. Likewise, the period of time of virus detection lasted longer in active surveillance compared with passive surveillance. Our results show that the mallard viruses from January 2017 were largely indistinguishable from the other $\mathrm{HPAl} \mathrm{H}_{5} \mathrm{~N} 8$ viruses, including those of tufted ducks, indicating that mallards might be more resistant to disease compared with other duck species, similarly to previous findings for HPAI $\mathrm{H}_{5} \mathrm{~N}_{1}$ in mallards [26] and might therefore act as a reservoir species.

Results of analyses at the whole genome level indicated that the HA, NA and NS genes of Dutch $\mathrm{H}_{5} \mathrm{~N} 8$ viruses were most closely related to $2014 \mathrm{HPAl} \mathrm{H}_{5} \mathrm{~N} 8$ group B Eastern China viruses, while the other five genes were derived from Eurasian LPAI viruses. This genetic makeup is similar to viruses detected in Russia (May 2016) and Germany (autumn/winter 2016) [11,15]. Compared with the May 2016 Russian viruses, viruses in the Netherlands showed similar new reassortment events for the NP and PA genes as was described for the German viruses [15] (Table 5).

In contrast to the 2014/15 European emergence of HPAI $\mathrm{H}_{5} \mathrm{~N} 8$, when a single lineage of HPAI spread across Europe, the chain of events during the 2016/17 HPAI $\mathrm{H}_{5}$ emergence shows more similarities to the 2014/15 situation in the United States (US), where the HPAI $\mathrm{H}_{5} \mathrm{~N} 8$ group A viruses reassorted with local LPAI viruses causing massive and long lasting detection in both poultry and wild birds and local die-offs in wild birds [6]. While this manuscript was in preparation, detections of HPAI 
Overview of highly pathogenic avian influenza H5 clade 2.3.4.4-specific antibody incidence in the Netherlands based on haemagglutination inhibition assays starting from the first wave of this virus in 2014/2015 up to February 2017

\begin{tabular}{|c|c|c|c|c|c|c|}
\hline \multirow{2}{*}{ Species } & \multicolumn{2}{|c|}{$2014 / 15^{a}$} & \multicolumn{2}{|c|}{$2015 / 16^{b}$} & \multicolumn{2}{|c|}{$2016 / 17^{c}$} \\
\hline & Positive/total & Percentage & Positive/total & Percentage & Positive/total & Percentage \\
\hline Eurasian wigeon & $12 / 78$ & $15.4 \%$ & $5 / 73$ & $6.8 \%$ & $3 / 104$ & $2.9 \%$ \\
\hline $\begin{array}{l}\text { Lesser white-fronted } \\
\text { goose }\end{array}$ & $1 / 3$ & $33.3 \%$ & 0 & $U$ & 0 & U \\
\hline Mute swan & $29 / 88$ & $33.0 \%$ & $5 / 24$ & $20.8 \%$ & $3 / 24$ & $12.5 \%$ \\
\hline Common coot & $1 / 84$ & $1.2 \%$ & $1 / 22$ & $4.5 \%$ & $0 / 35$ & $0 \%$ \\
\hline Black-headed gull & $0 / 262$ & $0.0 \%$ & $0 / 31$ & U & $1 / 88$ & $1.1 \%$ \\
\hline Mallard & $0 / 93$ & $0.0 \%$ & $0 / 18$ & $\mathrm{U}$ & $11 / 72$ & $15.3 \%$ \\
\hline Egyptian goose & $0 / 62$ & $0.0 \%$ & $1 / 28$ & $3.6 \%$ & $0 / 10$ & $0 \%$ \\
\hline Total & $43 / 940$ & $4.6 \%$ & $12 / 347$ & $3.5 \%$ & $18 / 431$ & $4.2 \%$ \\
\hline
\end{tabular}

U: unknown.

a Data previously published [10].

${ }^{b}$ Data (partly) previously published [10] and supplemented with Eurasian wigeon data from this study ( $\mathrm{n}=28$ ) from 1 March 2016.

c Data obtained in the current study from 23 October 2016 to 8 February 2017.

$\mathrm{H}_{5}$ clade 2.3.4.4 virus in Europe were still reported in Belgium, Luxembourg, the Netherlands and the United Kingdom [18], even though migrating birds had largely left their European wintering sites, suggesting that virus amplification was now occurring in local resident birds. This is a cause of concern, as establishment of HPAI viruses among wild birds is difficult to control and may give rise to a situation comparable to that in Asia with new outbreaks in wild birds and poultry not being caused by novel introductions of HPAI viruses from distant areas, but from within the local populations. It remains unclear, however, what drivers are responsible for the duration of virus circulation in a wild bird population, either long (US 2014/15 and Europe 2016/17) or short (Europe 2014/15), and based on current knowledge we cannot predict how the $\mathrm{H}_{5}$ situation among wild birds in Europe will evolve.

In case of introduction of new HPAl viruses, it would be highly beneficial to be able to target active surveillance to key species for virus detection to avoid excessive costs, sampling efforts, and inclusion of unnecessarily large numbers of animals. We therefore examined the use of experimental approaches for serology for the second time in an outbreak situation. To confirm serological data and to be able to determine the HPAI/LPAI and HPAI clade bias with some accuracy, we performed both $\mathrm{HI}$ and VN assays. Sera of 12 birds showed exclusive titres or a bias towards HPAI virus, seven to LPAI virus and seven remained ambiguous [24]. VN assays confirmed the presence of HPAI $\mathrm{H}_{5}$ clade $2.3 \cdot 4 \cdot 4$-specific antibodies in $14 / 18$ sera from October 2016 onwards and 1/2 from 1 March 2016. High cross-reactivity patterns and low initial titres in both assays showed that specifying biases towards one of the different HPAI $\mathrm{H}_{5}$ clades is very difficult. Further optimisation and validation of the assays are required to provide rough estimates of the seropositivity in subsequent years. Preliminary comparisons between the winters using the same $\mathrm{HI}$ assay starting from the 2014/15 winter show an outbreak-related incidence of HPAI H5 clade 2.3.4.4.-specific antibodies of o\% before 2014 , rising to $4.6 \%$ during the first outbreak of HPAI $\mathrm{H}_{5} \mathrm{~N} 8$ virus, decreasing to $3.5 \%$ in the $2015 / 16$ winter and rising to $4.2 \%$ in the $2016 / 17$ winter. Despite a similar antibody incidence between both outbreak periods, an apparent decreasing antibody incidence in two species detected throughout all three screening periods (Eurasian wigeons and mute swans) can be observed. This might be a consequence of differences in timing in peak prevalence between the first wave in 2014, with a very limited number of wild birds detected with a HPAI $\mathrm{H}_{5} \mathrm{~N} 8$ infection (i.e. local virus amplification) $[27,28]$ but high antibody incidence, and the current second wave, with substantial local virus replication and lower incidence of antibodies. These data could suggest that virus amplification in wigeons in 2014/15 took place before arrival of these birds in the Netherlands, whereas in 2016/17 virus amplification primarily took place within the Netherlands resulting in associated die-offs $[14,16]$. Unfortunately, we were unable to collect sera from wigeons late in the season in $2016 / 17$ to confirm increasing antibody incidence. However, the mallards that were tested later in the outbreak (February 2017) showed an increase in antibody incidence after a peak in virus detections a few weeks earlier compared with those tested earlier in the outbreak (November-December 2016).

Recently, clade 2.3.4.4 $\mathrm{H}_{5} \mathrm{~N} 6$ viruses started to circulate in both poultry and wild birds in south-east Asian counties [29] after their original detection in China [30], resembling HPAI $\mathrm{H}_{5} \mathrm{~N} 8$ dispersion of 2014 . In contrast to $\mathrm{HPAl} \mathrm{H}_{5} \mathrm{~N} 8$ viruses, these $\mathrm{H}_{5} \mathrm{~N} 6$ viruses have caused sporadic human infections, including fatalities [31]. Hence it will be important to monitor the movements of these viruses by intense monitoring of wild bird populations in the coming winter seasons. In terms of multiple 
intracontinental spread of $\mathrm{HPAl}_{5}$ viruses, global outbreaks were preceded by detections on breeding sites in Russia (Uvs-Nuur Lake district) and China (Qinghai Lake) after their initial detections in south-east Asia [11,32-35]. Increasing global collaborations and performing annual targeted active surveillance in China and on Russian breeding sites, and in Europe as autumn migration starts, will be important to provide early warning signals of HPAI virus dissemination.

\section{Acknowledgements}

The authors thank Anne van der Linden, Judith Guldemeester, Stefanie Vester, Sevgi Seven-Deniz, Celine Sweere, Rob Beerkens, Manon Briedé, Suzan Pas, Miranda de Graaf and Dennis de Meulder for providing technical assistance. We gratefully acknowledge Teunis en Joke de Vaal, Bert Pellegrom, Jan Berkouwer, Arie Keijzer, Jan en Lilian Slijkerman, Leon Kelder, Peter de Vries, Manon Kaandorp, Hans Zantinge, Jan Beekman, Alwin Hut, Peter Volten, Harma Scholten, Evert-Jan Epping, Ton Eggenhuizen, Henk Koffijberg, Cor van Aart, Henk ten Klooster, Sophie Brasseur, Sjoerd Dirksen, Fred Cottaar, Maarten van Kleinwee, Jose Verbeek, Jan Vegelin, Teja Curk, Chiel Boom, Martijn van der Sluijs, Kees Oosterbeek, Tijs van den Berg, Boena van Noorden, Jan Biemans, Rinus van Engelen, Jok van Bijnen, Peter van Run, Jan Vennik, Mardik Leopold, Roy Slaterus, Marko Cortel, Mariette Smit, Mr. Bronk, Jan van der Winden and the Kreupel tern research group for their involvement in obtaining the clinical samples. Last, we thank Ger van der Water for excellent logistical assistance.

We gratefully acknowledge the originating and submitting laboratories of the sequences from GISAID's EpiFlu Database on which this research is based. All submitters of data may be contacted directly via the GISAID website (www.gisaid. org). This work was supported by The Dutch Ministry of Economic Affairs, Horizon 2020 project COMPARE and NIAID/ NIH contract HHSN272201400008C.

\section{Conflict of interest}

None declared.

\section{Authors' contributions}

MP: performing serological assays, compiling the data and drafting the manuscript; TB and SV: excellent technical assistance in preparing, performing and interpreting serological assays; OV, RS, DE and PL: analysing samples for virus detection and sequencing; $\mathrm{HJ}$ and EK: initiation of the study, providing field data; JB, LB and TK: providing samples from passive surveillance; FM and GM: collecting field data; MK: responsible for diagnostic laboratory; RF: initiation of study; all authors: critically revised the manuscript.

\section{References}

1. Liu J, Xiao H, Lei F, Zhu Q, Qin K, Zhang XW, et al. Highly pathogenic $\mathrm{H}_{5} \mathrm{~N}_{1}$ influenza virus infection in migratory birds. Science. 2005;309(5738):1206. https://doi.org/10.1126/ science.1115273 PMID: 16000410

2. Ku KB, Park EH, Yum J, Kim JA, Oh SK, Seo SH. Highly pathogenic avian influenza $A\left(\mathrm{H}_{5} \mathrm{~N} 8\right)$ virus from waterfowl, South Korea, 2014. Emerg Infect Dis. 2014;20(9):1587-8. https://doi.org/10.3201/eid2009.140390 PMID: 25152954

3. Wu H, Peng X, Xu L, Jin C, Cheng L, Lu X, et al. Novel reassortant influenza $\mathrm{A}\left(\mathrm{H}_{5} \mathrm{~N} 8\right)$ viruses in domestic ducks, eastern China. Emerg Infect Dis. 2014;20(8):1315-8. https:// doi.org/10.3201/eid2008.140339 PMID: 25075453

4. Lee YJ, Kang HM, Lee EK, Song BM, Jeong J, Kwon YK, et al. Novel reassortant influenza $\mathrm{A}\left(\mathrm{H}_{5} \mathrm{~N} 8\right)$ viruses, South Korea, 2014. Emerg Infect Dis. 2014;20(6):1086-9. https://doi. org/10.3201/eid2006.140233 PMID: 24856098

5. Verhagen JH, Herfst S, Fouchier RA. How a virus travels the world. Science. 2015;347(6222):616-7. https://doi.org/10.1126/ science.aaa6724 PMID: 25657235

6. Lee DH, Bahl J, Torchetti MK, Killian ML, Ip HS, DeLiberto TJ, et al. Highly Pathogenic Avian Influenza Viruses and Generation of Novel Reassortants, United States, 2014-2015. Emerg Infect Dis. 2016;22(7):1283-5. https://doi.org/10.3201/ eid2207.160048 PMID: 27314845

7. Verhagen $J H$, van der Jeugd HP, Nolet BA, Slaterus R, Kharitonov SP, de Vries PP, et al. Wild bird surveillance around outbreaks of highly pathogenic avian influenza $\mathrm{A}\left(\mathrm{H}_{5} \mathrm{~N} 8\right)$ virus in the Netherlands, 2014, within the context of global flyways. Euro Surveill. 2015;20(12):21069. https://doi. org/10.2807/1560-7917.ES2015.20.12.21069 PMID: 25846491

8. Bouwstra RJ, Koch G, Heutink R, Harders F, van der Spek A, Elbers AR, et al. Phylogenetic analysis of highly pathogenic avian influenza $\mathrm{A}\left(\mathrm{H}_{5} \mathrm{~N} 8\right)$ virus outbreak strains provides evidence for four separate introductions and one betweenpoultry farm transmission in the Netherlands, November 2014. Euro Surveill. 2015;20(26):21174. https://doi. org/10.2807/1560-7917.ES2015.20.26.21174 PMID: 26159311

9. World Organisation for Animal Health (OIE). Update on highly pathogenic avian influenza in animals (type $\mathrm{H}_{5}$ and H7). Paris: OIE; 2015. Available from: http://www.oie.int/en/ animal-health-in-the-world/update-on-avian-influenza/2015/

10. Poen MJ, Verhagen JH, Manvell RJ, Brown I, Bestebroer TM, van der Vliet S, et al. Lack of virological and serological evidence for continued circulation of highly pathogenic avian influenza $\mathrm{H}_{5} \mathrm{~N} 8$ virus in wild birds in the Netherlands, 14 November 2014 to 31 January 2016. Euro Surveill. 2016;21(38):30349. https://doi.org/10.2807/1560-7917.ES.2016.21.38.30349 PMID: 27684783

11. Lee DH, Sharshov K, Swayne DE, Kurskaya O, Sobolev I, Kabilov M, et al. Novel Reassortant Clade 2.3.4.4 Avian Influenza $\mathrm{A}\left(\mathrm{H}_{5} \mathrm{~N} 8\right)$ Virus in Wild Aquatic Birds, Russia, 2016. Emerg Infect Dis. 2017;23(2):359-60. https://doi.org/10.3201/ eid2302.161252 PMID: 27875109

12. Zhou LC, Liu J, Pei EL, Xue WJ, Lyu JM, Cai YT, et al. Novel Avian Influenza $\mathrm{A}\left(\mathrm{H}_{5} \mathrm{~N} 8\right)$ Viruses in Migratory Birds, China, 2013-2014. Emerg Infect Dis. 2016;22(6):1121-3. https://doi. org/10.3201/eid2206.151754 PMID: 27192098

13. Nagarajan S, Kumar M, Murugkar HV, Tripathi S, Shukla S, Agarwal S, et al. Novel Reassortant Highly Pathogenic Avian Influenza ( $\left.\mathrm{H}_{5} \mathrm{~N} 8\right)$ Virus in Zoos, India. Emerg Infect Dis. 2017;23(4):717-9. https://doi.org/10.3201/eid2304.161886 PMID: 28117031

14. Beerens N, Heutink R, Bergervoet SA, Harders F, Bossers A, Koch G. Multiple Reassorted Viruses as Cause of Highly Pathogenic Avian Influenza A(H5N8) Virus Epidemic, the Netherlands, 2016. Emerg Infect Dis. 2017;23(12):1974-81. https://doi.org/10.3201/eid2312.171062 PMID: 29148396

15. Pohlmann A, Starick E, Harder T, Grund C, Höper D, Globig A, et al. Outbreaks among Wild Birds and Domestic Poultry Caused by Reassorted Influenza A(H5N8) Clade 2.3.4.4 Viruses, Germany, 2016. Emerg Infect Dis. 2017;23(4):633-6. https:// doi.org/10.3201/eid2304.161949 PMID: 28055819

16. Kleyheeg E, Slaterus R, Bodewes R, Rijks JM, Spierenburg $M A H$, Beerens N, et al. Deaths among Wild Birds during Highly Pathogenic Avian Influenza A(H5N8) Virus Outbreak, the Netherlands. Emerg Infect Dis. 2017;23(12):2050-4. https:// doi.org/10.3201/eid2312.171086 PMID: 29148372

17. World Organisation for Animal Health (OIE). Follow-up report No. 14, Report reference HPAI 2016/01 WB1, Reference OIE: 23566, Report Date 14/04/2017, Country: Netherlands. Paris: OIE; 2016. Available from: http://www.oie.int/en/ animal-health-in-the-world/update-on-avian-influenza/2017/

18. World Organisation for Animal Health (OIE). Update on highly pathogenic avian influenza in animals (types $\mathrm{H}_{5}$ and $\mathrm{H}_{7}$ ). Paris: OIE; 2017. Available from: http://www.oie.int/en/ animal-health-in-the-world/update-on-avian-influenza/2017/

19. Global Consortium for $\mathrm{H}_{5} \mathrm{~N} 8$ and Related Influenza Viruses. Role for migratory wild birds in the global spread of avian influenza H5N8. Science. 2016;354(6309):213-7. https://doi. org/10.1126/science.aaf8852 PMID: 27738169

20. Guindon S, Dufayard JF, Lefort V, Anisimova M, Hordijk W, Gascuel O. New algorithms and methods to estimate maximum-likelihood phylogenies: assessing the performance of PhyML 3.0. Syst Biol. 2010;59(3):307-21. https://doi. org/10.1093/sysbio/syq010 PMID: 20525638 
21. Huson DH, Scornavacca C. Dendroscope 3: an interactive tool for rooted phylogenetic trees and networks. Syst Biol. 2012;61(6):1061-7. https://doi.org/10.1093/sysbio/syso62 PMID: 22780991

22. Hirst GK. Studies of Antigenic Differences among Strains of Influenza a by Means of Red Cell Agglutination. J Exp Med. 1943;78(5):407-23. https://doi.org/10.1084/jem.78.5.407 PMID: 19871338

23. Richard M, Herfst S, van den Brand JM, Lexmond P, Bestebroer TM, Rimmelzwaan GF, et al. Low Virulence and Lack of Airborne Transmission of the Dutch Highly Pathogenic Avian Influenza Virus H5N8 in Ferrets. PLoS One. 2015;10(6):e0129827. https://doi.org/10.1371/journal.pone.0129827 PMID: 26090682

24. Gilbert M, Koel BF, Bestebroer TM, Lewis NS, Smith DJ, Fouchier RA. Serological evidence for non-lethal exposures of Mongolian wild birds to highly pathogenic avian influenza $\mathrm{H}_{5} \mathrm{~N}_{1}$ virus. PLoS One. 2014;9(12):e113569. https://doi. org/10.1371/journal.pone.0113569 PMID: 25502318

25. Selim AA, Erfan AM, Hagag N, Zanaty A, Samir AH, Samy M, et al. Highly Pathogenic Avian Influenza Virus ( $\left.\mathrm{H}_{5} \mathrm{~N} 8\right)$ Clade 2.3.4.4 Infection in Migratory Birds, Egypt. Emerg Infect Dis. 2017;23(6):1048-51. https://doi.org/10.3201/eid2306.162056 PMID: 28518040

26. Keawcharoen J, van Riel D, van Amerongen G, Bestebroer T, Beyer WE, van Lavieren R, et al. Wild ducks as long-distance vectors of highly pathogenic avian influenza virus ( $\left.\mathrm{H}_{5} \mathrm{~N}_{1}\right)$. Emerg Infect Dis. 2008;14(4):600-7. https://doi.org/10.3201/ eid1404.071016 PMID: 18394278

27. World Organisation for Animal Health (OIE). Update on highly pathogenic avian influenza in animals (types $\mathrm{H}_{5}$ and $\mathrm{H}_{7}$ ). Paris: OIE; 2014. Available from: http://www.oie.int/en/ animal-health-in-the-world/update-on-avian-influenza/2014/

28. World Organisation for Animal Health (OIE). Update on highly pathogenic avian influenza in animals (types $\mathrm{H}_{5}$ and $\mathrm{H}_{7}$ ). Paris: OIE; 2015. Available from: http://www.oie.int/en/ animal-health-in-the-world/update-on-avian-influenza/2015/

29. Si YJ, Lee IW, Kim EH, Kim YI, Kwon HI, Park SJ, et al. Genetic characterisation of novel, highly pathogenic avian influenza (HPAl) $\mathrm{H}_{5} \mathrm{~N} 6$ viruses isolated in birds, South Korea, November 2016. Euro Surveill. 2017;22(1):30434. https://doi. org/10.2807/1560-7917.ES.2017.22.1.30434 PMID: 28079520

30. Bi Y, Mei K, Shi W, Liu D, Yu X, Gao Z, et al. Two novel reassortants of avian influenza $A\left(\mathrm{H}_{5} \mathrm{~N} 6\right)$ virus in China. J Gen Virol. 2015;96(Pt 5):975-81. https://doi.org/10.1099/ vir.0.000056 PMID: 25604926

31. Zhang Y, Chen M, Huang Y, Zhu W, Yang L, Gao L, et al. Human infections with novel reassortant $\mathrm{H}_{5} \mathrm{~N} 6$ avian influenza viruses in China. Emerg Microbes Infect. 2017;6(6):e50. https://doi. org/10.1038/emi.2017.38 PMID: 28588293

32. Sharshov K, Silko N, Sousloparov I, Zaykovskaya A, Shestopalov A, Drozdov I. Avian influenza ( $\left.\mathrm{H}_{5} \mathrm{~N}_{1}\right)$ outbreak among wild birds, Russia, 2009. Emerg Infect Dis. 2010;16(2):349-51. https://doi.org/10.3201/eid1602.090974 PMID: 20113582

33. Marchenko VY, Susloparov IM, Kolosova NP, Goncharova NI, Shipovalov AV, Durymanov AG, et al. Influenza $\mathrm{A}\left(\mathrm{H}_{5} \mathrm{~N} 8\right)$ virus isolation in Russia, 2014. Arch Virol. 2015;160(11):2857-60. https://doi.org/10.1007/s00705-015-2570-4 PMID: 26306756

34. Marchenko VY, Susloparov IM, Komissarov AB, Fadeev A, Goncharova NI, Shipovalov AV, et al. Reintroduction of highly pathogenic avian influenza $\mathrm{A} / \mathrm{H}_{5} \mathrm{~N} 8$ virus of clade 2.3.4.4. in Russia. Arch Virol. 2017;162(5):1381-5. https://doi. org/10.1007/s00705-017-3246-z PMID: 28138776

35. Li M, Liu H, Bi Y, Sun J, Wong G, Liu D, et al. Highly Pathogenic Avian Influenza $\mathrm{A}\left(\mathrm{H}_{5} \mathrm{~N} 8\right)$ Virus in Wild Migratory Birds, Qinghai Lake, China. Emerg Infect Dis. 2017;23(4):637-41. https://doi. org/10.3201/eid2304.161866 PMID: 28169827

\section{License and copyright}

This is an open-access article distributed under the terms of the Creative Commons Attribution (CC BY 4.0) Licence. You may share and adapt the material, but must give appropriate credit to the source, provide a link to the licence, and indicate if changes were made.

This article is copyright of the authors, 2018. 